\title{
OEfeito da Expansão dos Institutos e das Universidades Federais sobre o Mercado de Trabalho
}

\section{The Effect of the Expansion of Federal Institutes and Universities on the Labor Market}

\author{
Ândrea Leite Bergmann ${ }^{\text {a }}$ \\ Felipe Garcia Ribeiro ${ }^{\mathrm{b}}$ \\ Thais Waideman Niquito ${ }^{\mathrm{C}}$ \\ Gibran Teixeira ${ }^{\mathrm{d}}$
}

\begin{abstract}
Resumo: Este estudo avalia o impacto da expansão, entre 2000 e 2010, das universidades e dos institutos federais de educação sobre a performance do mercado de trabalho dos municípios brasileiros contemplados. Especificamente, avalia-se o efeito sobre as taxas de atividade, ocupação e formalização da mão de obra e sobre indicadores de empreendedorismo. Utilizam-se os dados dos censos demográficos de 2000 e 2010, assim como as informações do Sistema Integrado de Monitoramento, Execução e Controle do Ministério da Educação (Simec) para montagem de um painel de municípios. A estratégia empírica adotada é o método de diferença em diferenças com uma especificação econométrica capaz de acomodar a presença de sinergia entre a expansão concomitante das duas instituições. Há evidências positivas de impacto e sinergias sobre a taxa de ocupação e a formalização dos postos de trabalho.
\end{abstract}

Palavras-chave: Educação federal. Mercado de trabalho. Sinergias.

\begin{abstract}
We evaluate the impact of the expansion of federal universities and institutes of education on the labor market performance of the Brazilian municipalities between 2000 and 2010. Specifically, we evaluate the effect of such expansion on labor activity, occupation and formalization rates and on entrepreneurship indicators. We use data from the 2000 and 2010 demographic censuses and from Sistema Integrado de Monitoramento, Execução e Controle do Ministério da Educação (Simec), for the assembly of a panel of municipalities. The empirical strategy adopted is the method of difference in differences with an econometric specification that allow for the possibility of synergy between the concomitant expansion of the two institutions. There is positive evidence of impact and synergies on the employment rate and the formalization of jobs.
\end{abstract}

a Instituto Federal de Educação, Ciência e Tecnologia Sul-rio-grandense (IFSul). Pelotas, Rio Grande do Sul, Brasil.

b Universidade Federal de Pelotas (UFPel), Programa de Pós-Graduação em Organizações e Mercados (PPGOM). Pelotas, Rio Grande do Sul, Brasil.

c Universidade do Estado de Santa Catarina (UDESC), Departamento de Ciências Econômicas. Florianópolis, Santa Catarina, Brasil.

d Universidade Federal do Rio Grande (FURG), Instituto de Ciências Econômicas, Administrativas e Contábeis (ICEAC), Programa de Pós-Graduação em Economia Aplicada (PPGE). Rio Grande, Rio Grande do Sul, Brasil. 
Keywords: Federal education. Labor market. Synergies.

JEL Classification: J21; O11; R58.

\section{1 lntrodução}

O presente estudo tem como objetivo avaliar o efeito da expansão das Universidades Federais (UFs) e dos Institutos Federais de Educação, Ciência e Tecnologia (IFs) sobre indicadores do mercado de trabalho dos municípios brasileiros afetados pela expansão entre os anos de 2000 a 2010. Especificamente, as dimensões do mercado de trabalho, para as quais os efeitos da expansão são avaliados, são as seguintes: a) taxas de atividade e de ocupação; b) taxa de formalização da mão de obra; e c) métricas de empreendedorismo. Todos os indicadores são computados por distintos grupos etários para a avaliação da existência de possíveis efeitos heterogêneos da expansão em função da idade das pessoas. ${ }^{1}$

Segundo Vinhais (2013), a expansão recente do ensino superior federal ocorreu em três fases. A primeira, entre 1998 e 2002, encarregou-se de ampliar a oferta de cursos nas sedes existentes. A segunda, principalmente entre 2003 e 2006, teve como objetivo a criação de novas universidades, bem como a criação e consolidação de campi no interior do país. Já a terceira e última fase concentrou-se na reestruturação das unidades. Esse processo se deu, principalmente, através do Programa de Apoio a Planos de Reestruturação e Expansão das Universidades Federais (Reuni), instituído pelo Decreto $n^{\circ}$ 6.096, de 24 de abril de 2007 (BRASIL, 2007).

A investigação sobre os indicadores de mercado de trabalhado citados no primeiro parágrafo é uma novidade na pesquisa do tema, uma vez que os estudos já realizados se concentram apenas nos efeitos sobre a dimensão renda. ${ }^{2}$ Mais ainda, as pesquisas mencionadas avaliaram apenas os efeitos da expansão das UFs, desconsiderando os efeitos da expansão dos IFs. Portanto, a presente pesquisa também avança por tentar medir o efeito, parcial e total, da expansão de cada componente e de toda a rede federal de educação. Para tanto, estima-se o efeito da expansão dos IFs condicional à expansão das UFs. Por sua vez, também se estima o efeito da expansão das UFs condicional à expansão dos IFs.

Ainda que ambas as instituições, universidades e institutos, classifiquem-se como instituições públicas federais de ensino, apresentam uma composição diferente nos níveis dos cursos. As universidades federais atuam apenas com cursos

\footnotetext{
$1 \quad$ Segundo a literatura de mercado de trabalho, em decorrência da baixa experiência profissional, indivíduos mais jovens tendem a enfrentar mais as seguintes adversidades: a) maiores obstáculos para conseguir emprego; b) ingresso inicial em piores postos de trabalho; c) salários mais baixos; e d) maiores riscos de demissão. Ver, por exemplo, Corseuil et al. (2014) e Piopiunik e Ryan (2012). Ver Vinhais (2013) e Niquito, Ribeiro e Portugal (2018).
} 
superiores, oferecendo cursos de graduação e de pós-graduação, enquanto os institutos federais atuam na educação superior, básica e profissional, oferecendo cursos técnicos (nível médio), tecnólogos (nível superior), licenciaturas e pós-graduação. Diante dessa configuração distinta entre as duas instituições, espera-se que as características e as habilidades dos alunos egressos de ambos os estabelecimentos de ensino tenham algum grau de distinção, com possibilidades de complementaridade, o que pode surtir em diferentes efeitos em termos de ocupações e condições do mercado de trabalho. Talvez, a existência simultânea de instituições de ensino que formem capital humano com diferentes conjuntos de saberes (complementares) possa gerar mais e melhores condições para o desenvolvimento da atividade empresarial (em razão da diversidade de competências da mão de obra local). O último ponto, por sua vez, pode repercutir em geração de inovação e de transversalidade do conhecimento, como indicam Mowery (2005) e Chiarini, Vieira e Zorzin (2012).

Desse modo, torna-se relevante também investigar a existência de sinergias entre a expansão dos IFs e das UFs. Por sinergias, nesse caso, entende-se investigar e tentar responder as seguintes questões: o efeito da expansão dos IFs sobre o mercado de trabalho é modificado diante da expansão das UFs? Por outro lado, o efeito da expansão das UFs sobre o mercado de trabalho é modificado diante da expansão dos IFs?

Para avaliar as questões destacadas, utiliza-se o método de diferença em diferenças com efeitos fixos de municípios. A escolha de tal metodologia reside tanto na natureza da política pública em questão, que permite a identificação de grupos distintos no que tange à exposição à política (municípios contemplados e municípios não contemplados com as expansões ao longo do tempo), quanto na disponibilidade de informações municipais antes e depois da expansão. Sobre o último ponto, as edições dos censos demográficos de 2000 e 2010 permitem a construção de um banco de dados com estrutura de painel de municípios com o antes e depois da expansão.

Em síntese, os resultados apontam que as construções de campi de IFs e UFs exerceram impactos, basicamente, sobre a ocupação e a formalização da mão de obra. Os resultados significativos são observados, principalmente, em municípios com população média, entre 2000 e 2010, menor do que 50 mil habitantes e entre os indivíduos mais jovens (18 a 29 anos de idade). Na empregabilidade da mão de obra, há evidências de sinergias positivas na construção de campi de IFs e UFs. Exercícios adicionais para verificar a relevância dos efeitos de curto prazo nos resultados observados indicam que as estimativas observadas devem estar mais associadas a melhorias na qualidade do capital humano e em outros indicadores de desenvolvimento (efeitos de longo prazo) do que com choques de curto prazo.

$\mathrm{O}$ artigo conta com esta introdução e mais cinco seções: na segunda é realizada uma revisão de literatura sobre os possíveis benefícios econômicos e 
sociais decorrentes da expansão da rede de ensino, com ênfase no ensino superior e profissional; na terceira são discutidas questões referentes à expansão dos IFs e UFs; na quarta é desenvolvida a base de dados e a metodologia em detalhes; na quinta são apresentados os resultados econométricos do estudo; e, por fim, na sexta são traçadas as considerações finais.

\section{Revisão de Literatura: Expansão da Educação e Benefícios}

Não foi apenas no Brasil que ocorreram esforços no sentido de massificar níveis mais avançados e específicos de educação. Ao final dos anos 1990 e começo dos anos 2000, houve forte expansão universitária nos demais países em desenvolvimento, que, junto com o Brasil, formavam os Brics (Brasil, Rússia, Índia, China e África do Sul). De acordo com Carnoy, Loyalka e Froumin (2013), a expansão massiva do ensino superior nos Brics teve significativo impacto sobre a oferta mundial de licenciados, principalmente nas áreas de engenharias e ciências da computação. Ainda segundo esses autores, na primeira década do século XXI as matrículas de nível de graduação aumentaram de 19 milhões, em 1999-2000, para mais de 40 milhões em 2009-2010. De longe, o país que mais aumentou o número de matriculados no ensino superior foi a China, que passou de menos de 3 milhões para quase 12 milhões de estudantes.

Segundo Florax (1994), há duas maneiras pelas quais instituições de ensino podem afetar os indicadores socioeconômicos de um país/região. O primeiro, de curto prazo, pode ser sintetizado como efeito gasto, provocado diretamente pela construção da infraestrutura necessária ao funcionamento das universidades e faculdades. O outro, de longo prazo, pode ser definido como efeito conhecimento. Trabalhadores mais educados são mais produtivos e capazes de implementar e lidar com novas tecnologias, o que, por sua vez, fomenta um ambiente propício à instalação de empresas, que, em última instância, pode acarretar aumento da demanda por trabalho especializado, geração de renda, etc.

Além disso, segundo Beeson e Montgomery (1993), universidades e faculdades podem afetar as economias locais por meio de suas atividades de pesquisa quando atraem recursos de fora e produzem inovação tecnológica devido à cooperação entre universidades e indústrias, como o caso do Vale do Silício, na Califórnia e a Rota $128 \mathrm{em}$ Boston. Em sua pesquisa, estes autores encontraram indícios de que as taxas de crescimento do emprego são positivamente correlacionadas com programas de universidades voltados à ciência e à engenharia, assim como aos financiamentos em pesquisa e desenvolvimento. Os autores concluíram que atividades universitárias podem afetar a demanda por trabalhadores com habilidades específicas. Moretti (2004) encontra, também para os Estados Unidos, que o aumento de trabalhadores com ensino superior no mercado de trabalho possui efeitos significativos (de baixa 
magnitude) nos rendimentos dos demais trabalhadores. Esse ponto indica a existência de externalidades positivas sobre o mercado de trabalho.

Nessa mesma perspectiva, Goddard e Chatterton (1999) destacam a importância das universidades no desenvolvimento regional. Porém, para que as universidades possam fomentar o progresso é preciso que ocorra um alinhamento entre agências de desenvolvimento regional e instituições de pesquisa a fim de criar sistemas de aprendizagem regional. Só assim, segundo os autores, ocorre a absorção da mão de obra qualificada, o estímulo ao empreendedorismo, o incentivo à criação e à expansão de inovação tecnológica e a consequente melhoria de bem-estar social das regiões.

Na China, Li e Xing (2010) documentam que a expansão universitária, além de ter aumentado a possibilidade de ingresso nas universidades, proporcionou uma elevação na probabilidade de inserção no mercado de trabalho, um resultado verificado principalmente entre os jovens egressos.

Vinhais (2013), para o Brasil, destaca que, através dos serviços de ensino, pesquisa, extensão e de outras atividades como conferências e seminários, as universidades são capazes de afetar economicamente as regiões onde estão, em decorrência do fato de que seu funcionamento gera demanda e oferta por bens e serviços, além de proporcionar no mercado de trabalho demanda e oferta de pessoas com maior qualificação profissional. $\mathrm{O}$ autor salienta, ainda, que os impactos advindos da instalação de uma universidade em uma região podem ser classificados como de curto e longo prazo. Os de curto prazo estão relacionados com as despesas e investimentos diretos da implantação da unidade de ensino (salários dos professores e funcionários, aumento na demanda de bens e serviços em função dos estudantes, etc.), enquanto os de longo prazo se referem à expansão do capital humano (aumento da escolaridade, qualificação da mão de obra e criação de novas empresas) e ao crescimento da área de pesquisa. São argumentos muito próximos ao de Florax (1994).

Empiricamente, para o Brasil, o próprio Vinhais (2013), discutido no parágrafo anterior, e Niquito, Ribeiro e Portugal (2018) investigam o efeito da expansão dos campi de UFs sobre medidas de renda dos municípios do país. Metodologicamente, Vinhais (2013) e Niquito, Ribeiro e Portugal (2018) são próximos a este trabalho, pois ambos utilizam o método de diferença em diferenças e os censos demográficos de 2000 e 2010. Porém, o primeiro autor fez pareamento por escore de propensão para a construção do grupo controle no período anterior à política pública de expansão da rede (ano 2000), enquanto os segundos autores tentaram mensurar os efeitos de equilíbrio geral sobre os municípios que não receberam diretamente os novos campi, mas que são vizinhos de municípios que receberam. Em termos de efeitos estimados, ambos estudos encontraram evidências de efeitos 
positivos da expansão das universidades sobre renda, situando-se tais efeitos entre $2,0 \%$ e $5,0 \% .^{3}$

No âmbito estadual, especificamente no estado do Paraná, Caldarelli, Camara e Perdigão (2015) pesquisam a relação entre as universidades paranaenses e o desenvolvimento dos municípios. Os autores utilizam como indicadores de desenvolvimento o Índice Firjan de Desenvolvimento Municipal (IFDM) e seus subíndices de emprego/renda, educação e saúde. Exploraram uma estrutura de dados em painel que abrangeu todos os municípios paranaenses entre os anos de 2006 a 2010. Os resultados obtidos pelo método de efeitos fixos apontaram que a existência de uma universidade estadual (sede ou campus) é positiva e estatisticamente significante em todos os modelos considerados no estudo, sendo o efeito mais intenso sobre o indicador de emprego/renda.

No tocante à educação profissional, não foram encontrados estudos, nacionais ou internacionais, que associassem a presença de sedes ou campi de instituições ofertantes de ensino profissional sobre quaisquer tipos de variáveis. Contudo, há pesquisas que tentaram medir as causalidades e correlações existentes entre formação profissional e rendimentos/ inserção no mercado de trabalho. Pode-se mencionar os estudos realizados por Gontijo e Amaral (2015) e Oliva, Ribeiro e Souza (2015). Em ambas as pesquisas, foram observadas evidências de que a educação profissional pode abrir portas no mercado de trabalho, tanto através de maior empregabilidade quanto através de maiores salários.

\section{Expansão da Educação Profissional, Tecnológica e Superior Federal entre 2000 e 2010}

Dados do Instituto Nacional de Estudos e Pesquisas Educacionais Anísio Teixeira (Inep), autarquia federal vinculada ao Ministério da Educação (MEC), revelam que, entre 2000 e 2010, os Institutos Federais (antigos Centros Federais de Educação Tecnológica - Cefets) passaram de 11 para 37 instituições, enquanto as universidades, de 39 para 58. A respeito das vagas oferecidas de nível superior, as universidades possuíam 112.826 vagas de cursos de graduação presenciais, em 2000, e 218.152 vagas, em 2010, um aumento de quase 94\% (BRASIL, 2015). Já para a educação profissional, considerando-se os Cefets, para o ano de 2000, e os IFs, para 2010, ${ }^{4}$ as vagas alocadas à graduação presencial passaram de 5.277 para 29.811, totalizando uma expansão de mais de 450\%. Além disso, as matrículas da

3 Como será melhor discutido na metodologia, o método deste trabalho também é o de diferença em diferenças, mas com especificações distintas em relação às utilizadas por Vinhais (2013) e Niquito, Ribeiro e Portugal (2018).

4 Os Cefets foram transformados em IFs somente em 2008, através da Lei no 11.892/2008 (BRASIL, 2008). 
educação profissional de nível médio passaram de 56.579 para 89.218 entre 2001 e 2010 (+57\%). ${ }^{5}$ A Figura 1 apresenta a evolução do número de universidades desagregado por capital e interior. O crescimento da educação superior federal foi fortemente direcionado ao interior do país. Em 2002, existiam 148 campi distribuídos em 114 municípios. No período compreendido entre 2003 e 2010, o número de campi passou para 274, um crescimento de $85 \%$ (BRASIL, 2012a). Contudo, conforme destacado por Niquito, Ribeiro e Portugal (2018), boa parte das universidades procedeu de outras instituições existentes. ${ }^{6}$

Figura 1 - Evolução do número de universidades federais no Brasil, por localização (capital e interior), entre os anos de 2000 e 2010

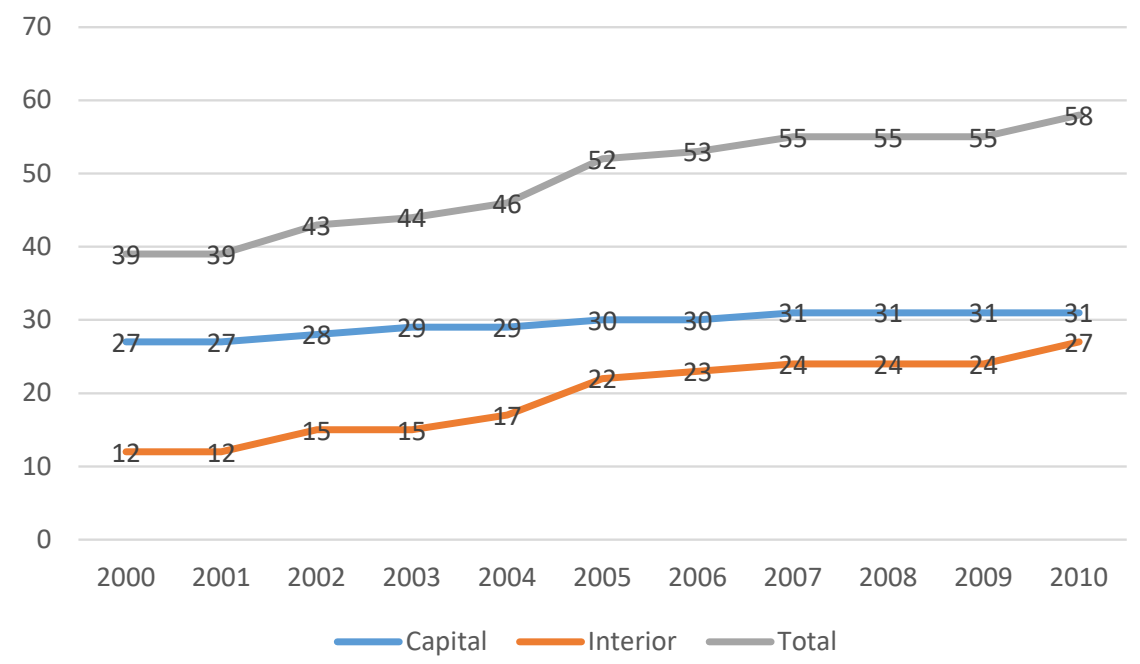

Fonte: Elaboração própria a partir de dados fornecidos pelo Inep em Sinopses Estatísticas da Educação Superior.

A crescente expansão das universidades também foi acompanhada por um expressivo aumento nas contratações de funcionários ligados às atividades administrativas e educacionais. Segundo o Inep, o número de funções docentes ${ }^{7}$ (em exercício e afastados) aumentou de 47.922 para 74.059 (+54\%) entre 2000 e 2010.

5 As sinopses estatísticas do Inep de 2000 não possuem informações sobre a educação profissional de nível médio, bem como não apresentam dados sobre o número de vagas e de instituições em nenhum dos anos.

6 Como já dito e será ainda melhor discutido na metodologia, a criação de novos campi em municípios que não tinham nada previamente é o que interessa nesta pesquisa. A relação dos municípios que receberam novos campi universitários e os preexistentes pode ser requerida junto aos autores deste estudo.

7 Vínculo que um docente possui com uma instituição de ensino superior (IES). Um mesmo docente pode ter mais de uma função docente, a depender da quantidade de IES a que esteja vinculado. Fonte: INEP (BRASIL, 2012b). 
Já em relação aos funcionários técnico-administrativos (em exercício e afastados), houve aumento de 65.726 para 86.577 (+31\%). Além disso, segundo Vinhais (2013), os gastos do governo federal destinados à expansão das universidades federais representaram um montante em torno de $R \$ 120$ bilhões entre 2000 e 2010.

Em relação aos IFs, a primeira fase de expansão da rede compreendeu o período de 2003 a 2010. Houve, nessa fase, a implantação de 214 novos campi, com destaque para o grande enfoque na instalação das novas unidades no interior do país (ANDRADE, 2014). Em números, de acordo com as informações extraídas do Sistema Integrado de Monitoramento, Execução e Controle do Ministério da Educação (Simec) (BRASIL, [2019b]), das 214 novas unidades quase 95\% foram construídas nos municípios do interior. Em termos de gastos, entre 2001 e 2010, foi despendido um montante de quase $\mathrm{R} \$ 15$ bilhões na educação profissional (BRASIL, [2019a]). Adicionalmente, assim como no caso das universidades, houve expressivo aumento do número de contratações, matrículas/vagas, cursos oferecidos e estabelecimentos.

\section{Dados e Estratégia Empírica}

A base de dados desta pesquisa é obtida das edições de 2000 e 2010 do censo demográfico, elaborado pelo IBGE. Dessas edições do censo, são obtidas as informações referentes ao mercado de trabalho (empregabilidade, formalização, medidas de empreendedorismo e taxa de atividade) e às demais características demográficas utilizadas como covariadas nas equações. A estrutura dos dados à disposição permite a composição de um banco de dados em painel de municípios. Os microdados dos censos demográficos com informações nos níveis de indivíduos e domicílios são facilmente agrupáveis no nível de municípios. Por exemplo, com informações referentes ao status de mercado de trabalho de cada indivíduo (ocupado ou desocupado), é possível calcular a taxa de ocupação de cada município.

Já as informações referentes à expansão dos campi de IFs e UFs foram obtidas do Simec (BRASIL, [2019b]), por meio de seu módulo público. O Simec contém informações da localidade e do nome da unidade, tanto dos campi preexistentes quanto dos criados e os previstos. Neste estudo, são considerados como municípios afetados pela política de expansão da educação federal apenas os municípios que não possuíam nenhum campus antes da expansão e que receberam algum campus entre 2000 e 2010. Adota-se esse procedimento para a captura somente do efeito dos novos campi sem a influência dos estabelecimentos pré-expansão, dos quais muitos já estavam em funcionamento por vários anos.

A utilização de mínimos quadrados ordinários $(\mathrm{MQO})$ para estimar equações que relacionem as variáveis de mercado de trabalho com as variáveis referentes à expansão da rede de ensino federal gera, provavelmente, estimativas viesadas do efeito 
da expansão. Isso ocorre porque possivelmente algumas das características não observáveis dos municípios são correlacionadas simultaneamente com a política de expansão da rede e com o desempenho do mercado de trabalho dos municípios.

Assim, para investigar a existência de um possível efeito causal da expansão (criação de novos campi) dos IFs e das UFs sobre o desempenho de alguns indicadores de mercado de trabalho dos municípios, utiliza-se o método de diferença em diferenças com efeito fixo do município. Com esse método não experimental de avaliação de políticas públicas no contexto específico do presente trabalho, o pressuposto que se assume para identificação da relação causal entre expansão dos centros de ensino e o desempenho do mercado de trabalho é que, na ausência da criação dos campi entre 2000 e 2010, as trajetórias das variáveis dependentes dos municípios que receberam os novos campi seriam idênticas às trajetórias das variáveis dependentes dos municípios que não receberam os novos campi. Assumindo-se esse pressuposto como válido, o desempenho, entre 2000 e 2010, dos indicadores de mercado de trabalho dos municípios não contemplados pela expansão da rede federal de ensino serve de contrafactual para avaliação dos efeitos da política pública.

Formalmente, a equação que será estimada é a seguinte:

$$
\begin{gathered}
y_{\mathrm{mt}}=\alpha_{0}+\alpha_{l} I F_{\mathrm{mt}}+\alpha_{2} U F_{\mathrm{mt}}+\alpha_{3} I F_{\mathrm{mt}} * U F_{\mathrm{mt}}+\sum_{j=1}^{k} \beta_{\mathrm{j}} x_{\mathrm{mtj}}+\theta A n o_{\mathrm{t}}+\lambda_{\mathrm{mt}}+v_{\mathrm{mt}} \\
\operatorname{para} m=1, \ldots \mathrm{n} \text { e } t=2000-2010
\end{gathered}
$$

As variáveis $I F_{\mathrm{mt}}$ e $U F_{\mathrm{mt}}$ são variáveis binárias que capturam o fato do município $m$ estar exposto, no período $t$, à abertura de um novo campus de IF e UF respectivamente. Portanto, para todos os municípios, essas variáveis são iguais a zero em 2000. Já para aqueles municípios que tiveram abertura de IF entre 2000 e 2010, a variável $I F_{\mathrm{mt}}$ assume valor um em 2010. Analogamente, se nesse período ocorreu a abertura de campus de UF no município $m$, a variável $U F_{\mathrm{mt}}$ assume valor um em 2010. Como dito anteriormente, este trabalho avança em relação aos demais por tentar estimar o efeito da expansão dos IFs condicional à expansão de UFs nos municípios, bem como estimar o efeito da expansão das UFs condicional à expansão dos IFs. Isso se dá pela inclusão simultânea de ambas as variáveis: $I F_{\mathrm{mt}}$ e $U F_{\mathrm{mt}}$.

Já a variável $I F_{\mathrm{mt}}{ }^{*} U F_{\mathrm{mt}}$ é simplesmente a interação entre as variáveis binárias $I F_{\mathrm{mt}}$ e $U F_{\mathrm{mt}}$. O coeficiente associado ao termo da interação, $\alpha_{3}$, em tese, captura o efeito da sinergia entre a expansão dos IFs e das UFs sobre os municípios que receberam as duas intervenções dentro do período de análise. ${ }^{8}$

$8 \quad$ A ideia de inserir a interação de variáveis que representam intervenções distintas (políticas públicas) para a avaliação da sinergia entre elas é baseada no trabalho de Garcia, Helfand e Souza (2016). Nesse estudo, os autores tentaram mensurar a sinergia dos programas Bolsa família e Programa Nacional de Fortalecimento da Agricultura Familiar (Pronaf) sobre algumas medidas de 
A variável dependente, $y_{\mathrm{mt}}$, representa para o município $m$ no ano $t$ uma das cinco seguintes variáveis de mercado de trabalho: taxa de ocupação, taxa de formalização da mão de obra, taxa de participação de profissionais por conta própria no total da população, taxa de participação de empregadores no total da população e taxa de atividade (população economicamente ativa (ocupados e desocupados) sobre população em idade ativa). A primeira das variáveis dependentes tem como intuito verificar se a expansão da rede de ensino federal exerceu algum efeito nas possibilidades de trabalho nas economias locais, municipais. A taxa de ocupação é obtida da razão entre o número de pessoas ocupadas pelo total de pessoas ocupadas e desocupadas de cada município.

Já a segunda medida tenta captar se a expansão da rede de ensino federal exerceu algum efeito sobre a "qualidade" dos postos de trabalho, uma vez que se sabe da literatura de mercado de trabalho que, postos formais, em geral, são melhores do que os informais (RAMOS, 2007; CARDOSO, 2007; CURI; MENEZES-FILHO, 2004). A variável de formalização é obtida pela razão entre o número de trabalhadores formais pelo total de ocupados. Foram considerados formais trabalhadores classificados nas seguintes faixas: a) empregados com carteira de trabalho assinada; b) militares do exército, da marinha, da aeronáutica e da polícia militar ou corpo de bombeiros; c) empregados pelo regime jurídico dos funcionários públicos; e d) empregadores. O aumento da formalização da força de trabalho pode ser um dos canais que justificam os resultados positivos da expansão das UFs sobre a renda dos municípios, obtidos por Vinhais (2013) e Niquito, Ribeiro e Portugal (2018). Uma vez que, se os postos formais em relação aos postos informais, podem proporcionar maior produtividade, em última instância também podem acarretar maiores salários.

As variáveis dependentes taxa de empregadores e taxa de profissionais por conta própria visam captar efeitos da expansão das instituições de ensino federal sobre a atividade empreendedora, que se sabe da literatura de crescimento econômico, em especial dos modelos schumpeterianos, que é chave para explicar o crescimento de longo prazo (AGHION; HOWITT, 1992). Contudo, é importante explicar porque as duas medidas não foram agrupadas. Sobre a taxa de empregadores, seguiu-se parte dos estudos dedicados a estudar empreendedorismo que define empreendedores exclusivamente como aqueles indivíduos que são empregadores. Segundo Castellani e Lora (2014), empregadores são empreendedores de oportunidades porque criam novos negócios, geram empregos, ousam em práticas, etc. Pode-se dizer que são agentes capazes de realizar inovação. Por outro lado, trabalhadores por conta própria são empreendedores por necessidades em função da falta de outras opções. Assim, as motivações que levam ao engajamento no empreendedorismo são distintas entre empregadores e profissionais por conta própria, o que motiva o não agrupamento das duas categorias em uma única. Além disso, a

produtividade e de desenvolvimento de estabelecimentos agrícolas do Brasil entre 1996 e 2006. 
posição de ocupação conta própria é classificada na literatura, geralmente, como um posto de trabalho informal (NERI, 2002; REIS; ULYSSEA, 2005; ULYSSEA, 2006).

No entanto, conforme destacado por Neri (2002), há uma corrente de estudos empíricos para os EUA e Reino Unido em que os movimentos dos trabalhadores rumo à empregos por conta própria são utilizados como proxy para a criação de empreendedorismo na economia, uma vez que os trabalhadores por conta própria também assumem o risco da atividade. Há dessa forma algum mérito de inclusão dos profissionais por conta própria na atividade empreendedora em decorrência disso (PARKER, 2018).

Por fim, a variável dependente taxa de atividade visa buscar potenciais efeitos da expansão de institutos e universidades sobre o tamanho da força de trabalho do município. Ela foi calculada como a razão entre as pessoas pertencentes à população economicamente ativa (pessoas ocupadas e aquelas que não têm ocupação, mas que estejam buscando emprego) e as pessoas em idade ativa. ${ }^{9}$

Já as $k$ variáveis representadas em $x_{\mathrm{mtj}}$ são as seguintes covariadas demográficas: a proporção de homens do município, a proporção de brancos, a proporção de pessoa de 15 a 24 anos, de 25 a 59 anos, de 60 ou mais anos de idade e a proporção de pessoas residentes em domicílios localizados na zona urbana. Para cada uma das cinco variáveis dependentes, a equação 1 foi estimada com todas essas covariadas. A utilização dessas covariadas faz com que as trajetórias das variáveis dependentes dos municípios afetados pela expansão da rede federal de ensino sejam comparadas com as trajetórias das mesmas variáveis dependentes de municípios não afetados pela expansão, mas similares, em média, em características demográficas.

Os níveis em 2000 de cada uma das covariadas também estão entre as covariadas utilizadas nas regressões. Os níveis prévios são utilizados para que a comparação entre os municípios afetados pela expansão com os não afetados esteja livre de efeitos relacionados à decisão da alocação dos novos campi com base em características demográficas e sociais prévias, ou no potencial futuro baseado nas informações prévias de 2000. Assim, espera-se que parte dos fatores capazes de atrapalhar a identificação da relação causal de interesse esteja controlada.

Outra importante covariada utilizada é o nível do PIB per capita em 2000. Segundo Khandker, Koolwal e Samad (2009), ainda que as especificações de diferença em diferenças (estimadas por MQO ou por efeitos fixos) controlem por importantes características, condições iniciais das variáveis dependentes podem desempenhar importante papel em sua variação ao longo do tempo. No caso do presente trabalho, imagina-se que as condições iniciais da economia, provavelmente correlacionadas com as condições iniciais dos indicadores de mercado de

9 No censo de 2010, são consideradas com idade ativa aquelas pessoas com 10 anos de idade ou mais. Como este estudo constrói as variáveis dependentes para diferentes grupos etários, como será visto, considera-se como em idade ativa a população total para cada faixa etária investigada. 
trabalho, possam afetar a variação dos indicadores de mercado de trabalho ao longo do tempo. Tal fato pode se dar tanto pela consagrada relação existente entre desempenho econômico e mercado de trabalho (Lei de Okhun), quanto pelo fato de que a expansão da rede federal de ensino pode ter sido direcionada aos municípios com determinadas características iniciais de performance econômica. Assim, controlando pelo nível inicial do PIB per capita, reduz-se a possibilidade de que ocorra viés nas estimativas de diferença em diferenças motivado pela não aleatoriedade da participação na política pública.

Por fim, a variável $A n o_{t}$ é também uma variável binária cujo uso na equação tem por intuito captar o efeito de choques ao longo do tempo que atinjam os indicadores de mercado de trabalho dos municípios da mesma forma. Portanto, assume valor zero para as informações de 2000 e um para as informações de 2010. O termo $\lambda_{\mathrm{m}}$ é o componente não observável dos municípios correlacionado com a expansão dos campi e capaz de afetar as variáveis dependentes. Já o termo $v_{\mathrm{mt}}$ é o componente não observável que varia ao longo do tempo, mas é idiossincrático. Sob a hipótese do método de diferença em diferença com efeito fixo (condicional aos fatores fixos não observáveis dos municípios ao longo do tempo e a algumas características observáveis, as trajetórias das variáveis dependentes entre os municípios que receberam e os que não receberam a expansão do ensino federal são paralelas na ausência da expansão), acredita-se que os coeficientes estimados de $\alpha_{1}, \alpha_{2}$ e $\alpha_{3}$ captem o efeito causal das aberturas dos IFs e das UFs e da sinergia existente entre a abertura dos dois tipos de instituições.

A identificação dos impactos da criação de novos campi de IFs e UFs, assim como os efeitos da interação entre as duas expansões, está baseada nas variações da expansão das instituições entre os municípios ao longo do tempo. Para tornar isso mais claro, tomam-se da equação 1 os quatro seguintes valores esperados condicionais a diferentes status no que tange à criação de um novo campus de IF, mas que tenha havido criação de um campus de UF:

$$
\begin{aligned}
E\left[y_{m t} \mid I F_{m t}=\right. & \left.0, U F_{m t}=1, \bar{X}_{j}, A n o_{t}=0, \lambda_{m}\right] \\
& =\alpha_{0}+\sum_{j=1}^{k} \beta_{j} \bar{X}_{j}+\lambda_{m} \\
& +E\left[v_{m t} \mid I F_{m t}=0, U F_{m t}=1, \bar{X}_{j}, A n o_{t}=0, \lambda_{m}\right]
\end{aligned}
$$




$$
\begin{gathered}
E\left[y_{m t} \mid I F_{m t}=0, U F_{m t}=1, \bar{X}_{j}, A n o_{t}=1, \lambda_{m}\right] \\
=\alpha_{0}+\alpha_{2}+\sum_{j=1}^{k} \beta_{j} \bar{X}_{j}+\theta+\lambda_{m} \\
+E\left[v_{m t} \mid I F_{m t}=0, \overline{U F}, \bar{X}_{j}, A n o_{t}=1, \lambda_{m}\right] \\
E\left[y_{m t} \mid I F_{m t}=1, U F_{m t}=1, \bar{X}_{j}, A n o_{t}=0, \lambda_{m}\right] \\
=\alpha_{0}+\sum_{j=1}^{k} \beta_{j} \bar{X}_{j}+\lambda_{m} \\
+E\left[v_{m t} \mid I F_{m t}=1, U F_{m t}=1, \bar{X}_{j}, A n o_{t}=0, \lambda_{m}\right] \\
E\left[y_{m t} \mid I F_{m t}=1, U F_{m t}=1, \bar{X}_{j}, A n o_{t}=1, \lambda_{m}\right] \\
=\alpha_{0}+\alpha_{1}+\alpha_{2}+\alpha_{3} * \overline{U F}+\sum_{j=1}^{k} \beta_{j} \bar{X}_{j}+\theta+\lambda_{m} \\
+E\left[v_{m t} \mid I F_{m t}=1, U F_{m t}=1, \bar{X}_{j}, A n o_{t}=1, \lambda_{m}\right]
\end{gathered}
$$

Em seguida, subtraindo-se a equação 3 da 2 e 5 da 4, obtém-se, respectivamente, as equações 6 e 7:

$$
\begin{aligned}
\theta+\alpha_{2}+\left\{E\left[v_{m t} \mid I F_{m t}=0, U F_{m t}=1, \bar{X}_{j}, A n o_{t}=1, \lambda_{m}\right]\right. \\
\left.-E\left[v_{m t} \mid I F_{m t}=0, U F_{m t}=1, \bar{X}_{j}, A n o_{t}=0, \lambda_{m}\right]\right\} \\
\alpha_{1}+\alpha_{2}+\alpha_{3}+\theta+E\left\{\left[v_{m t} \mid I F_{m t}=1, U F_{m t}=1, \bar{X}_{j}, A n o_{t}=1, \lambda_{m}\right]\right. \\
\left.-E\left[v_{m t} \mid I F_{m t}=1, U F_{m t}=1, \bar{X}_{j}, A n o_{t}=0, \lambda_{m}\right]\right\}
\end{aligned}
$$

Por último, tomando-se a diferença entre as equações 6 e 7 e considerando-se que as trajetórias das variáveis dependentes entre os municípios que receberam e os que não receberam a expansão do ensino federal são paralelas na ausência da expansão (hipótese central do método diferença em diferenças), tem-se que: 


$$
\begin{gathered}
\left\{\begin{array}{c}
E\left[y_{m t} \mid I F_{m t}=1, U F_{m t}=1, \bar{X}_{j}, A n o_{t}=1, \lambda_{m}\right] \\
E\left[y_{m t} \mid I F_{m t}=1, U F_{m t}=1, \bar{X}_{j}, A n o_{t}=0, \lambda_{m}\right]
\end{array}\right\} \\
-\left\{\begin{array}{c}
E\left[y_{m t} \mid I F_{m t}=0, U F_{m t}=1, \bar{X}_{j}, A n o_{t}=1, \lambda_{m}\right] \\
- \\
E\left[y_{m t} \mid I F_{m t}=0, U F_{m t}=1, \bar{X}_{j}, A n o_{t}=0, \lambda_{m}\right]
\end{array}\right\}= \\
\alpha_{1}+\alpha_{3} .
\end{gathered}
$$

A expressão 8 pode ser interpretada como o impacto da expansão dos IFs sobre as variáveis dependentes (taxa de ocupação, formalização, trabalhadores por conta própria, empregadores e taxa de atividade) em municípios que tenham experimentado também a construção de campi de UFs. É fácil checar, através de exercício similar - fazendo-se, pois, na ausência de construção de campi de UFs, o efeito da expansão dos IFs é apenas . Assim, o coeficiente, capta a sinergia existente entre a expansão conjunta de IFs e UFs. O efeito da expansão dos IFs é modificado quando há também expansão das UFs, caso exista sinergia. Analogamente, o efeito da expansão das UFs será, quando há também expansão de IFs, e apenas quando não haja.

As cinco medidas de mercado de trabalho que servem de variáveis dependentes neste estudo foram calculadas para três grupos demográficos distintos: pessoas com 18 ou mais anos de idade, pessoas com idade entre 18 e 29 anos, e pessoas com 50 ou mais anos de idade. O primeiro corte, de pessoas com 18 ou mais anos de idade, foi assim realizado pelo fato de que IFs e UFs provavelmente afetam com maior probabilidade as oportunidades no mercado de trabalho de pessoas adultas, e não de crianças e adolescentes em idade escolar. Já o grupo de 18 a 29 anos de idade contempla boa parte das pessoas que estão tentando sua primeira colocação profissional. Em decorrência da falta de experiência e insuficiência de informações sobre suas reais habilidades e interesses, é mais difícil o ingresso dos jovens no mercado de trabalho. Além disso, em geral, observam-se menores salários e maior rotatividade para essas pessoas (OLIVA; RIBEIRO; SOUZA, 2015; CORSEUIL et al., 2014; PIOPIUNIK; RYAN, 2012). Dessa forma, é possível que a expansão da rede de ensino federal possa ter efeitos diferentes entre os jovens, o que, se identificado, é fundamental para gestores de políticas públicas.

Por último, sobre o grupo etário de pessoas com 50 ou mais anos de idade, as alterações demográficas que o Brasil vem experimentando ao longo do último meio século (aumento da expectativa de vida, melhora da qualidade de vida, queda na fecundidade, etc.) têm gerado questões importantes sobre o tempo de contribuição à previdência e/ou a idade mínima para aposentadoria. Possivelmente, a população 
será demandada a ficar no mercado de trabalho por mais tempo no futuro. Assim, todos os aspectos ligados à inserção e à manutenção das pessoas com 50 ou mais anos de idade no mercado de trabalho são de fundamental interesse para políticas públicas. A educação formal e profissional dessas pessoas insere-se nesse contexto.

Exploram-se ainda efeitos heterogêneos da expansão da educação federal em função da localização geográfica e do tamanho dos municípios. Estimam-se todas as equações para os municípios das regiões Norte e Nordeste agrupados e, também, para os municípios das regiões Centro-Oeste, Sudeste e Sul agrupados. Além disso, em decorrência do fato de a política de expansão do ensino federal ter tido clara intenção de promover o desenvolvimento do interior do país, como já dito, procedem-se regressões para outras duas amostras. A primeira contém exclusivamente municípios com menos de cem mil habitantes na média dos anos de 2000 e 2010 e a segunda, municípios com menos de 50 mil habitantes nessa mesma média. Foram excluídos de todas as amostras os municípios criados entre 2000 e 2010 (58 municípios de um universo de mais de 5000 municípios no país).

Seguindo a orientação de Bertrand, Duflo e Mullainathan (2004), para melhorar os aspectos de inferência estatística quando aplicado o método de diferença em diferenças, todas as estimações da equação 1 foram realizadas com clusters por municípios para os erros das regressões. Assim, evitam-se problemas de correlação serial e heterocedasticidade. Além disso, as equações estimadas foram ponderadas pelo tamanho médio da população dos municípios entre 2000 e 2010, já que provavelmente o desempenho do mercado de trabalho pode estar correlacionado com o tamanho dos municípios.

\section{Resultados}

A Tabela 1 apresenta as estatísticas descritivas das variáveis utilizadas. ${ }^{10} \mathrm{~A}$ taxa de ocupação das pessoas com 50 ou mais anos de idade é maior do que as taxas observadas para os outros dois grupos (jovens e o geral das pessoas com 18 anos ou mais). Em 2000, a taxa de ocupação média dos municípios para as pessoas com 50 ou mais anos de idade foi de $93,75 \%$, enquanto para as pessoas de 18 a 29 anos foi de $84,05 \%$. Em 2010, houve aumento nessa média para os dois grupos: $88,25 \%$, entre os mais jovens, e $96,73 \%$ entre os mais velhos.

10 A descrição de cada uma das variáveis utilizadas neste estudo pode ser consultada no Quadro 1do Apêndice A. 
Tabela 1 - Estatísticas descritivas das variáveis de mercado de trabalho, expansão da rede federal de ensino e características demográficas dos municípios em 2000 e 2010

\begin{tabular}{|c|c|c|c|c|c|}
\hline \multirow[b]{2}{*}{ Variáveis } & \multirow[b]{2}{*}{ Observações } & \multicolumn{2}{|c|}{2000} & \multicolumn{2}{|c|}{2010} \\
\hline & & Média & $\begin{array}{l}\text { Desvio } \\
\text { Padrão } \\
\end{array}$ & Média & $\begin{array}{l}\text { Desvio } \\
\text { Padrão }\end{array}$ \\
\hline Ocupação 18 ou mais & 5.507 & 89,20 & 5,97 & 92,84 & 4,33 \\
\hline Ocupação 18 a 29 & 5.507 & 84,05 & 8,16 & 88,25 & 6,58 \\
\hline Ocupação 50 ou mais & 5.507 & 93,75 & 5,09 & 96,73 & 2,92 \\
\hline Formal 18 ou mais & 5.507 & 35,65 & 15,35 & 42,23 & 16,59 \\
\hline Formal 18 a 29 & 5.507 & 37,35 & 17,57 & 46,30 & 19,98 \\
\hline Formal 50 ou mais & 5.507 & 25,88 & 14,17 & 31,44 & 14,44 \\
\hline C_Própria 18 ou mais & 5.507 & 16,21 & 7,59 & 14,92 & 7,64 \\
\hline C_Própria 18 a 29 & 5.507 & 10,40 & 5,91 & 10,03 & 6,52 \\
\hline C_Própria 50 ou mais & 5.507 & 16,94 & 8,19 & 15,04 & 7,68 \\
\hline Empregador 18 ou mais & 5.507 & 1,17 & 0,98 & 0,84 & 0,76 \\
\hline Empregador 18 a 29 & 5.507 & 0,49 & 0,59 & 0,41 & 0,52 \\
\hline Empregador 50 ou mais & 5.507 & 1,22 & 1,23 & 0,81 & 0,82 \\
\hline Tx de Ativ. 18 ou mais & 5.507 & 54,88 & 10,52 & 55,77 & 11,63 \\
\hline Tx de Ativ 18 a 29 & 5.507 & 60,23 & 13,31 & 64,19 & 14,63 \\
\hline Tx de Ativ 50 ou mais & 5.507 & 34,14 & 8,71 & 33,24 & 9,49 \\
\hline Expansão_IF's & 5.507 & 0,00 & 0,00 & 0,04 & 0,19 \\
\hline Expansão_Univ. & 5.507 & 0,00 & 0,00 & 0,02 & 0,14 \\
\hline Interação & 5.507 & 0,00 & 0,00 & 0,01 & 0,07 \\
\hline Urbano & 5.507 & 57,37 & 23,29 & 64,16 & 21,92 \\
\hline Homem & 5.507 & 50,78 & 1,68 & 50,51 & 1,70 \\
\hline Branco & 5.507 & 52,63 & 25,62 & 47,49 & 23,73 \\
\hline idade0a14anos & 5.507 & 32,20 & 5,74 & 25,46 & 5,07 \\
\hline idade15a24anos & 5.507 & 19,54 & 2,18 & 17,86 & 2,03 \\
\hline idade 25 a 59 anos & 5.507 & 39,14 & 5,50 & 44,60 & 4,49 \\
\hline idade60anos & 5.507 & 9,11 & 2,67 & 12,07 & 3,31 \\
\hline Alfabetizados & 5.507 & 79,11 & 12,21 & 84,04 & 9,75 \\
\hline
\end{tabular}

Fonte: Elaboração própria.

Quanto à taxa de formalização, para os três grupos etários analisados constata-se um aumento na formalização média dos municípios de aproximadamente 10 pontos percentuais. No grupo de pessoas com 18 a 29 anos de idade, a taxa de formalização subiu de uma média de 37,35\% para 46,30\%. Destaca-se o fato de que a formalização média dos municípios é maior entre as pessoas com 18 a 29 anos do que entre as pessoas com 50 anos ou mais de idade.

Já a taxa de atividade é maior entre as pessoas de 18 a 29 anos em comparação com as demais faixas etárias aqui investigadas. Em 2010, 64,19\% das pessoas 
entre 18 e 29 anos faziam parte da força de trabalho, frente a 55,77\% daquelas com 18 anos ou mais e a 33,24\% das com mais de 50 anos. Com exceção da última, nota-se um aumento da taxa de atividade entre 2000 e 2010.

Sobre a expansão da rede de ensino federal, a Tabela 1 revela que apenas 3,6\% dos municípios da amostra receberam expansão dos IFs. Em relação a novos campi de UFs, esse número é de 2,1\%. Por último, a proporção de municípios que receberam simultaneamente campi de IFs e UFs representa apenas meio por cento do total. A Tabela 1 ainda apresenta informações médias municipais das proporções médias de homens, brancos, residentes na zona urbana e de pessoas por faixas etárias.

Para a análise descritiva dos dados, a amostra também foi segmentada segundo a expansão da rede de educação federal. Há, então, o conjunto dos municípios tratados (que receberam IF, UF ou ambos) e o conjunto dos municípios controle (que não foram contemplados com a expansão da rede de ensino federal). Os resultados podem ser vistos na Tabela 8 do Apêndice A. Destaca-se a similaridade, em termos das variáveis de interesse, entre os grupos de tratados e controle.

Os resultados econométricos estão presentes nas Tabelas 2 a 6, sendo que as colunas (1) e (2) diferem pelo conjunto de covariadas inseridos na estimação. A especificação preferida para análise dos resultados é aquela que foi estimada com o maior número de covariadas, pois provavelmente é a que oferece os melhores contrafactuais para a avaliação da expansão da rede federal de educação. A Tabela 2 apresenta as estimativas obtidas da equação 1 para a amostra que contém municípios de todas as regiões do país.

Tabela 2 - Efeito expansão IFs e UFs sobre mercado de trabalho: diferença em diferenças

\begin{tabular}{lcccccc}
\hline & \multicolumn{2}{c}{ Efeito IFs } & \multicolumn{2}{c}{ Efeito UFs } & \multicolumn{2}{c}{ Efeito interação } \\
\hline Var. Dep. & $\mathbf{( 1 )}$ & $\mathbf{( 2 )}$ & $\mathbf{( 1 )}$ & $\mathbf{( 2 )}$ & $\mathbf{( 1 )}$ & $\mathbf{( 2 )}$ \\
\cline { 2 - 7 } & \multicolumn{7}{c}{$\mathbf{1 8}$ ou mais anos de idade } \\
\hline Empregado & 0,2448 & $-0,4914^{*}$ & 0,3701 & $-0,1387$ & 1,0360 & $1,1188^{* *}$ \\
& $(0,2991)$ & $(0,2579)$ & $(0,3626)$ & $(0,2617)$ & $(0,6923)$ & $(0,5143)$ \\
Formal & 0,6731 & 0,4170 & $-0,3296$ & $-0,0771$ & 0,2920 & $-0,2606$ \\
& $(0,4337)$ & $(0,3560)$ & $(0,4659)$ & $(0,4625)$ & $(0,7910)$ & $(0,7711)$ \\
C_Própria & 0,2212 & 0,0679 & 0,2102 & 0,1579 & 0,1504 & 0,1112 \\
& $(0,1663)$ & $(0,1741)$ & $(0,1918)$ & $(0,2013)$ & $(0,2854)$ & $(0,3171)$ \\
Empregador & $-0,0711^{*}$ & $-0,0452$ & $-0,0158$ & $-0,0219$ & 0,1162 & 0,1240 \\
& $(0,0428)$ & $(0,0420)$ & $(0,0535)$ & $(0,0524)$ & $(0,1088)$ & $(0,1160)$ \\
Taxa de & 0,1858 & 0,3658 & 0,1777 & 0,2925 & $-0,6202$ & $-0,7068$ \\
atividade & $(0,2207)$ & $(0,2466)$ & $(0,3298)$ & $(0,3256)$ & $(0,8057)$ & $(0,5896)$ \\
\hline & 0,1336 & $-0,6522 *$ & 0,1987 & $-0,4428$ & 1,0918 & $1,3232^{* *}$ \\
\hline & $(0,3965)$ & $(0,3614)$ & $(0,4735)$ & $(0,3631)$ & $(0,7695)$ & $(0,6485)$ \\
\hline Empregado & \multicolumn{7}{c}{ continua... }
\end{tabular}


conclusão.

\begin{tabular}{|c|c|c|c|c|c|c|}
\hline \multirow[b]{2}{*}{ Var. Dep. } & \multicolumn{2}{|c|}{ Efeito IFs } & \multicolumn{2}{|c|}{ Efeito UFs } & \multicolumn{2}{|c|}{ Efeito interação } \\
\hline & (1) & (2) & (1) & (2) & (1) & (2) \\
\hline \multicolumn{7}{|c|}{18 a 29 anos de idade } \\
\hline \multirow[t]{2}{*}{ Formal } & $1,2857^{*}$ & 0,8254 & 0,0604 & 0,3753 & $-0,6613$ & $-1,3848$ \\
\hline & $(0,6591)$ & $(0,5117)$ & $(0,6480)$ & $(0,5876)$ & $(1,1567)$ & $(1,1246)$ \\
\hline \multirow[t]{2}{*}{ C_Própria } & 0,0493 & 0,1313 & $-0,1487$ & $-0,0693$ & 0,2767 & 0,1747 \\
\hline & $(0,1751)$ & $(0,1761)$ & $(0,1936)$ & $(0,2237)$ & $(0,2997)$ & $(0,3682)$ \\
\hline \multirow[t]{2}{*}{ Empregador } & $-0,0132$ & $-0,0009$ & 0,0066 & 0,0063 & 0,0021 & 0,0048 \\
\hline & $(0,0250)$ & $(0,0251)$ & $(0,0307)$ & $(0,0312)$ & $(0,0503)$ & $(0,0518)$ \\
\hline \multirow[t]{2}{*}{$\begin{array}{l}\text { Taxa de } \\
\text { atividade }\end{array}$} & 0,3929 & $0,9775 * *$ & $-0,1867$ & 0,2528 & $-1,3117$ & $-1,7686^{* *}$ \\
\hline & $(0,3836)$ & $(0,3874)$ & $(0,4371)$ & $(0,4278)$ & $(1,1250)$ & $(0,8166)$ \\
\hline \multicolumn{7}{|c|}{50 ou mais anos de idade } \\
\hline \multirow[t]{2}{*}{ Empregado } & 0,3768 & $-0,3860$ & 0,4449 & $-0,0138$ & 1,1041 & $1,1485 * *$ \\
\hline & $(0,2714)$ & $(0,2499)$ & $(0,4081)$ & $(0,2719)$ & $(0,6965)$ & $(0,4771)$ \\
\hline \multirow[t]{2}{*}{ Formal } & $0,7504^{* * *}$ & $0,5838^{*}$ & 0,3206 & 0,4479 & 0,1305 & $-0,1109$ \\
\hline & $(0,3207)$ & $(0,3227)$ & $(0,4228)$ & $(0,4434)$ & $(0,9626)$ & $(0,9166)$ \\
\hline \multirow[t]{2}{*}{ C_Própria } & 0,3231 & $-0,1273$ & 0,1004 & $-0,1639$ & 0,3231 & 0,3820 \\
\hline & $(0,2103)$ & $(0,1725)$ & $(0,3201)$ & $(0,2240)$ & $(0,4570)$ & $(0,3481)$ \\
\hline \multirow[t]{2}{*}{ Empregador } & 0,0128 & 0,0318 & 0,0561 & 0,0359 & 0,0109 & 0,0300 \\
\hline & $(0,0641)$ & $(0,0575)$ & $(0,0708)$ & $(0,0691)$ & $(0,1610)$ & $(0,1639)$ \\
\hline \multirow[t]{2}{*}{$\begin{array}{l}\text { Taxa de } \\
\text { atividade }\end{array}$} & 0,4928 & $-0,1241$ & $-0,0488$ & $-0,4655$ & 0,1099 & 0,3168 \\
\hline & $(0,4157)$ & $(0,2772)$ & $(0,6216)$ & $(0,4200)$ & $(1,0742)$ & $(0,7718)$ \\
\hline Dummy de ano & Sim & Sim & Sim & $\mathrm{Sim}$ & Sim & Sim \\
\hline Controles (A) & Sim & Sim & Sim & Sim & Sim & Sim \\
\hline Controles (B) & Não & Sim & Não & Sim & Não & Sim \\
\hline Observações & 11.014 & 11.014 & 11.014 & 11.014 & 11.014 & 11.014 \\
\hline
\end{tabular}

Fonte: Elaboração própria.

Nota: Controles (A): proporção de homens do município, proporção de brancos, proporções de pessoas de 15 a 24 anos, de 25 a 59 anos, de 60 ou mais anos de idade e proporção de pessoas residentes em domicílios localizados na zona urbana; Controles (B): o nível, em 2000, da proporção de homens do município, da proporção de brancos, das proporções de pessoas de 15 a 24 anos, de 25 a 59 anos, de 60 ou mais anos de idade, da proporção de pessoas residentes em domicílios localizados na zona urbana e do PIB per capita; Desvios padrão entre parênteses; Níveis de significância: * $\mathrm{p}<0.10,{ }^{* *} \mathrm{p}<0.05,{ }^{* * *} \mathrm{p}<0.01$.

Para os três grupos etários analisados, há evidências de sinergias positivas da criação de IFs e UFs sobre a ocupação. Isso indica que o efeito da criação de um campus de IF é potencializado quando há a criação de um campus de UF. Em municípios que observaram expansão de campi de IFs e UFs entre 2000 e 2010, o efeito da criação dos IFs sobre a empregabilidade das pessoas de 18 anos ou mais foi de um aumento médio de 0,63 pontos percentuais (p.p.) $(-0,49+1,12)$. Para as pessoas com 18 a 29 anos de idade, o aumento médio foi de 0,67 p.p. $(-0,65+1,32)$, 
e para as pessoas com 50 anos ou mais o mesmo foi de 1,15 p.p. É importante mencionar os efeitos negativos estimados sobre a empregabilidade, para os dois primeiros grupos etários (maiores de 18 anos e pessoas de 18 a 29 anos), nos municípios em que a expansão dos IFs não foi acompanhada de expansão das UFs. Houve também um coeficiente negativo estimado indicando sinergia negativa entre IFs e UFs sobre a taxa de atividade para o grupo de pessoas entre 18 a 29 anos. No entanto, nos municípios com expansão de IFs essa interação significa que altera o efeito positivo da expansão dos IFs sobre empregabilidade.

Já sobre os efeitos da expansão das UFs, apenas se materializaram nos municípios que experimentaram simultaneamente a criação das duas instituições. Esse resultado é consequência direta do fato de que nenhum coeficiente estimado associado à variável que capta a expansão das universidades foi significativo estaticamente.

Sobre os indicadores de mercado de trabalho das pessoas com 18 ou mais anos de idade, nenhum efeito positivo da expansão da rede federal de ensino se observa nos municípios sem expansão conjunta de IFs e UFs. Há, contudo, efeito negativo da expansão dos IFs sobre o percentual de empregados: -0,5 (p.p.), significativo a $10 \%$.

Quando se analisam os efeitos levando-se em consideração diferentes grupos etários, um resultado similar é encontrado na população jovem, com impacto negativo de 0,65 p.p., também significativo a 10\%. Para esse grupo etário, também é encontrado efeito positivo da criação de institutos federais sobre a taxa de atividade $(0,98$ p.p., significativo a 5\%). Já entre as pessoas de 50 anos ou mais, foi encontrado efeito positivo sobre a formalização no mercado de trabalho: 0,58 p.p., significativo a $10 \%$.

Resultados diferentes são obtidos quando se avaliam os efeitos da expansão da rede de ensino superior em uma amostra composta apenas com municípios das regiões Norte e Nordeste, conforme a Tabela 3.

Tabela 3 - Efeito expansão dos IFs e UFs sobre o mercado de trabalho: diferença em diferenças (Norte e Nordeste)

\begin{tabular}{lcccccc}
\hline & \multicolumn{2}{c}{ Efeito IFs } & \multicolumn{2}{c}{ Efeito UFs } & \multicolumn{2}{c}{ Efeito interação } \\
\hline Var. Dep. & $\mathbf{( 1 )}$ & $\mathbf{( 2 )}$ & $\mathbf{( 1 )}$ & $\mathbf{( 2 )}$ & $\mathbf{( 1 )}$ & $\mathbf{( 2 )}$ \\
\cline { 2 - 7 } & \multicolumn{7}{c}{$\mathbf{1 8}$ ou mais anos de idade } & & \\
\hline Empregado & 0,9569 & 0,0458 & 0,0136 & $-0,6956^{*}$ & 1,2933 & 1,0139 \\
& $(0,5909)$ & $(0,4372)$ & $(0,3995)$ & $(0,3984)$ & $(1,0806)$ & $(1,0906)$ \\
Formal & $1,1003^{*}$ & $0,8491^{*}$ & 1,0857 & 1,1168 & 1,0670 & 0,6064 \\
& $(0,5801)$ & $(0,4621)$ & $(0,7428)$ & $(0,7140)$ & $(1,2820)$ & $(1,1814)$ \\
C_Própria & 0,4065 & $-0,1297$ & 0,5762 & 0,0861 & 0,7677 & 0,3721 \\
& $(0,2920)$ & $(0,2747)$ & $(0,3790)$ & $(0,3757)$ & $(0,8071)$ & $(0,6720)$ \\
Empregador & $-0,0655$ & $-0,0451$ & $-0,1009$ & $-0,1021$ & $-0,0338$ & $-0,0048$ \\
& $(0,0779)$ & $(0,0685)$ & $(0,0729)$ & $(0,0689)$ & $(0,1684)$ & $(0,1637)$ \\
Taxa de & 0,5465 & 0,3939 & $1,0110^{* *}$ & 0,6830 & 1,4804 & 1,0676 \\
atividade & $(0,3422)$ & $(0,3761)$ & $(0,4978)$ & $(0,4669)$ & $(0,9217)$ & $(0,9805)$ \\
& \multicolumn{7}{c}{}
\end{tabular}


conclusão.

\begin{tabular}{|c|c|c|c|c|c|c|}
\hline \multirow{2}{*}{ Var. Dep. } & \multicolumn{2}{|c|}{ Efeito IFs } & \multicolumn{2}{|c|}{ Efeito UFs } & \multicolumn{2}{|c|}{ Efeito interação } \\
\hline & (1) & (2) & (1) & (2) & (1) & (2) \\
\hline \multicolumn{7}{|c|}{18 a 29 anos de idade } \\
\hline \multirow{2}{*}{ Empregado } & 1,1123 & 0,1594 & $-0,3461$ & $-1,2077^{* *}$ & 2,0793 & 1,8282 \\
\hline & $(0,7706)$ & $(0,6360)$ & $(0,5216)$ & $(0,5203)$ & $(1,3869)$ & $(1,3561)$ \\
\hline \multirow[t]{2}{*}{ Formal } & $2,3486 * * *$ & $1,6188^{* *}$ & 1,5205 & 1,1652 & 2,8554 & 1,8730 \\
\hline & $(0,8819)$ & $(0,6296)$ & $(0,9879)$ & $(0,8961)$ & $(1,7892)$ & $(1,4597)$ \\
\hline \multirow[t]{2}{*}{ C_Própria } & 0,0330 & $-0,1836$ & 0,1715 & $-0,0307$ & 0,1050 & $-0,0472$ \\
\hline & $(0,2475)$ & $(0,2578)$ & $(0,3608)$ & $(0,3691)$ & $(0,6999)$ & $(0,6614)$ \\
\hline \multirow[t]{2}{*}{ Empregador } & $-0,0403$ & $-0,0340$ & 0,0033 & 0,0081 & $-0,0053$ & 0,0086 \\
\hline & $(0,0435)$ & $(0,0414)$ & $(0,0380)$ & $(0,0374)$ & $(0,1203)$ & $(0,1203)$ \\
\hline \multirow[t]{2}{*}{$\begin{array}{l}\text { Taxa de } \\
\text { atividade }\end{array}$} & 0,4941 & $0,7986 *$ & 0,7267 & $0,8489^{*}$ & 0,5095 & 0,1367 \\
\hline & $(0,4438)$ & $(0,4497)$ & $(0,4993)$ & $(0,4744)$ & $(1,0802)$ & $(0,9644)$ \\
\hline \multicolumn{7}{|c|}{50 ou mais anos de idade } \\
\hline \multirow[t]{2}{*}{ Empregado } & $1,0746^{* *}$ & 0,2558 & 0,1004 & $-0,4018$ & 0,1465 & $-0,1234$ \\
\hline & $(0,5444)$ & $(0,4041)$ & $(0,3814)$ & $(0,3160)$ & $(1,0551)$ & $(0,9424)$ \\
\hline \multirow[t]{2}{*}{ Formal } & 0,6700 & 0,5655 & $1,6361 * *$ & $1,5517^{* *}$ & $-0,8762$ & $-1,3070$ \\
\hline & $(0,5625)$ & $(0,5223)$ & $(0,7510)$ & $(0,7023)$ & $(1,5627)$ & $(1,7295)$ \\
\hline \multirow[t]{2}{*}{ C_Própria } & 0,7542 & $-0,1977$ & 0,2397 & $-0,6012$ & 1,5029 & 0,9671 \\
\hline & $(0,4663)$ & $(0,3525)$ & $(0,5034)$ & $(0,4271)$ & $(1,1063)$ & $(0,8044)$ \\
\hline \multirow[t]{2}{*}{ Empregador } & 0,0511 & 0,0610 & $-0,0568$ & $-0,0902$ & $-0,0508$ & $-0,0311$ \\
\hline & $(0,0934)$ & $(0,0830)$ & $(0,0919)$ & $(0,0885)$ & $(0,2130)$ & $(0,2113)$ \\
\hline \multirow[t]{2}{*}{$\begin{array}{l}\text { Taxa de } \\
\text { atividade }\end{array}$} & 0,6823 & $-0,5101$ & $-0,4836$ & $-1,5919^{* * *}$ & 2,6416 & 1,8400 \\
\hline & $(0,6797)$ & $(0,4541)$ & $(0,6866)$ & $(0,5716)$ & $(1,7442)$ & $(1,6187)$ \\
\hline Dummy de ano & Sim & Sim & Sim & Sim & Sim & Sim \\
\hline Controles (A) & Sim & Sim & Sim & Sim & Sim & Sim \\
\hline Controles (B) & Não & Sim & Não & Sim & Não & Sim \\
\hline Observações & 4.472 & 4.472 & 4.472 & 4.472 & 4.472 & 4.472 \\
\hline
\end{tabular}

Fonte: Elaboração própria.

Nota: Controles (A): proporção de homens do município, proporção de brancos, proporções de pessoas de 15 a 24 anos, de 25 a 59 anos, de 60 ou mais anos de idade e proporção de pessoas residentes em domicílios localizados na zona urbana; Controles (B): o nível, em 2000, da proporção de homens do município, da proporção de brancos, das proporções de pessoas de 15 a 24 anos, de 25 a 59 anos, de 60 ou mais anos de idade, da proporção de pessoas residentes em domicílios localizados na zona urbana e do PIB per capita; Desvios padrão entre parênteses; Níveis de significância: ${ }^{*} \mathrm{p}<0.10,{ }^{* *} \mathrm{p}<0.05,{ }^{* * *} \mathrm{p}<0.01$.

Destacam-se os efeitos positivos da expansão dos IFs sobre a formalização das pessoas com 18 anos ou mais e das pessoas com idade entre 18 a 29 anos: 0,85 p.p. e 1,62 p.p. respectivamente. Por outro lado, as estimativas indicaram impactos negativos da expansão das UFs sobre a empregabilidade nesses mesmos grupos. Para as pessoas com 50 ou mais anos de idade, a criação de campi de UFs exerceu efeito 
positivo sobre a formalização, estimado em 1,55 p.p., significativo a 5\%, e efeito negativo sobre a taxa de atividade, de 1,59 p.p., significativo a 1\%. Nessa amostra - municípios das regiões Norte e Nordeste - não há evidências de sinergias.

Já os resultados obtidos para a amostra que contém municípios das regiões Centro-Oeste, Sudeste e Sul (Tabela 4) os efeitos são semelhantes àqueles observados para a amostra total, com impactos negativos da expansão dos IFs sobre a ocupação das pessoas com 18 anos de idade ou mais e dos mais jovens: -0,86 p.p. e -1,18 p.p., respectivamente, ambos significativos a 1\%.

Tabela 4 - Efeito expansão dos IFs e UFs sobre o mercado de trabalho: diferença em diferenças (Centro-Oeste, Sudeste e Sul)

\begin{tabular}{|c|c|c|c|c|c|c|}
\hline \multirow[b]{2}{*}{ Var. Dep. } & \multicolumn{2}{|c|}{ Efeito IFs } & \multicolumn{2}{|c|}{ Efeito UFs } & \multicolumn{2}{|c|}{ Efeito interação } \\
\hline & (1) & (2) & (1) & (2) & (1) & (2) \\
\hline \multicolumn{7}{|c|}{18 ou mais anos de idade } \\
\hline \multirow[t]{2}{*}{ Empregado } & $-0,2707$ & $-0,8592^{* * *}$ & $0,8103^{*}$ & 0,3389 & 0,6140 & 0,7342 \\
\hline & $(0,3175)$ & $(0,3030)$ & $(0,4399)$ & $(0,3033)$ & $(0,8060)$ & $(0,5541)$ \\
\hline \multirow[t]{2}{*}{ Formal } & 0,3263 & 0,2489 & $-0,8776$ & $-0,7095$ & 0,4847 & 0,0647 \\
\hline & $(0,5794)$ & $(0,4048)$ & $(0,5611)$ & $(0,5021)$ & $(0,8850)$ & $(0,8407)$ \\
\hline \multirow[t]{2}{*}{ C_Própria } & 0,0194 & 0,0802 & 0,1934 & 0,1741 & $-0,0014$ & 0,0182 \\
\hline & $(0,1996)$ & $(0,1539)$ & $(0,1701)$ & $(0,1854)$ & $(0,2857)$ & $(0,2862)$ \\
\hline \multirow[t]{2}{*}{ Empregador } & $-0,0609$ & $-0,0391$ & 0,0285 & 0,0283 & 0,1165 & 0,0859 \\
\hline & $(0,0518)$ & $(0,0508)$ & $(0,0752)$ & $(0,0744)$ & $(0,1316)$ & $(0,1380)$ \\
\hline \multirow[t]{2}{*}{$\begin{array}{l}\text { Taxa de } \\
\text { atividade }\end{array}$} & $-0,0062$ & 0,3809 & 0,0462 & 0,0662 & $-0,9121$ & $-0,7713$ \\
\hline & $(0,2973)$ & $(0,2928)$ & $(0,4497)$ & $(0,4079)$ & $(0,8648)$ & $(0,6419)$ \\
\hline \multicolumn{7}{|c|}{18 a 29 anos de idade } \\
\hline \multirow[t]{2}{*}{ Empregado } & $-0,5623$ & $-1,1811^{* * *}$ & 0,7511 & 0,1501 & 0,5691 & 0,8997 \\
\hline & $(0,4211)$ & $(0,3881)$ & $(0,5776)$ & $(0,4184)$ & $(0,9118)$ & $(0,7032)$ \\
\hline \multirow[t]{2}{*}{ Formal } & 0,5595 & 0,4644 & $-0,4045$ & $-0,1302$ & $-0,7496$ & $-1,2955$ \\
\hline & $(0,8131)$ & $(0,5538)$ & $(0,8129)$ & $(0,6934)$ & $(1,2663)$ & $(1,2115)$ \\
\hline \multirow[t]{2}{*}{ C_Própria } & 0,0420 & 0,2399 & $-0,2439$ & $-0,1293$ & 0,3093 & 0,1665 \\
\hline & $(0,2461)$ & $(0,1670)$ & $(0,2218)$ & $(0,2182)$ & $(0,3514)$ & $(0,3589)$ \\
\hline \multirow[t]{2}{*}{ Empregador } & 0,0084 & 0,0225 & 0,0020 & $-0,0045$ & $-0,0012$ & $-0,0045$ \\
\hline & $(0,0303)$ & $(0,0298)$ & $(0,0476)$ & $(0,0496)$ & $(0,0650)$ & $(0,0679)$ \\
\hline \multirow[t]{2}{*}{$\begin{array}{l}\text { Taxa de } \\
\text { atividade }\end{array}$} & 0,4547 & $1,1634^{* * *}$ & $-0,3857$ & $-0,1526$ & $-1,5284$ & $-1,7919^{* *}$ \\
\hline & $(0,5498)$ & $(0,5064)$ & $(0,5863)$ & $(0,5158)$ & $(1,2705)$ & $(0,9071)$ \\
\hline
\end{tabular}

50 ou mais anos de idade

\begin{tabular}{lllllll}
\hline Empregado & $-0,2350$ & $-0,8700^{* * *}$ & $0,8825^{*}$ & 0,3955 & 0,8250 & $0,9615^{*}$ \\
\hline & & & & continua...
\end{tabular}


conclusão.

\begin{tabular}{lcccccc}
\hline & \multicolumn{2}{c}{ Efeito IFs } & \multicolumn{2}{c}{ Efeito UFs } & \multicolumn{2}{c}{ Efeito interação } \\
\hline Var. Dep. & $\mathbf{( 1 )}$ & $\mathbf{( 2 )}$ & $\mathbf{( 1 )}$ & $\mathbf{( 2 )}$ & $\mathbf{( 1 )}$ & $\mathbf{( 2 )}$ \\
\cline { 2 - 7 } & \multicolumn{7}{c}{$\mathbf{5 0}$ ou mais anos de idade } \\
\hline \multirow{2}{*}{ Formal } & $(0,3021)$ & $(0,3174)$ & $(0,4709)$ & $(0,3732)$ & $(0,7410)$ & $(0,5613)$ \\
& $0,7378^{*}$ & $0,6902^{*}$ & $-0,2050$ & $-0,1538$ & 0,3174 & 0,2736 \\
C_Própria & $(0,3860)$ & $(0,4055)$ & $(0,4868)$ & $(0,4845)$ & $(1,0088)$ & $(1,0062)$ \\
& $-0,0951$ & $-0,1885$ & 0,3585 & 0,0921 & $-0,1357$ & 0,1873 \\
Empregador & $(0,1930)$ & $(0,1790)$ & $(0,2349)$ & $(0,1999)$ & $(0,3732)$ & $(0,3499)$ \\
& $-0,0003$ & 0,0317 & 0,1297 & 0,1126 & $-0,0413$ & $-0,0364$ \\
Taxa de & $(0,0782)$ & $(0,0687)$ & $(0,0965)$ & $(0,0907)$ & $(0,1921)$ & $(0,1951)$ \\
atividade & 0,2033 & 0,1089 & 0,9218 & 0,2594 & $-1,3286$ & $-0,3380$ \\
& $(0,4744)$ & $(0,3100)$ & $(0,6662)$ & $(0,5492)$ & $(1,1222)$ & $(0,9442)$ \\
\hline Dummy de & Sim & Sim & Sim & Sim & Sim & Sim \\
ano & Sim & Sim & Sim & Sim & Sim & Sim \\
Controles (A) & Não & Sim & Não & Sim & Não & Sim \\
Controles (B) & 6.542 & 6.542 & 6.542 & 6.542 & 6.542 & 6.542 \\
Observações & 6 & & & &
\end{tabular}

Fonte: Elaboração própria.

Nota: Controles (A): proporção de homens do município, proporção de brancos, proporções de pessoas de 15 a 24 anos, de 25 a 59 anos, de 60 ou mais anos de idade e proporção de pessoas residentes em domicílios localizados na zona urbana; Controles (B): o nível, em 2000, da proporção de homens do município, da proporção de brancos, das proporções de pessoas de 15 a 24 anos, de 25 a 59 anos, de 60 ou mais anos de idade, da proporção de pessoas residentes em domicílios localizados na zona urbana e do PIB per capita; Desvios padrão entre parênteses; Níveis de significância: ${ }^{*} \mathrm{p}<0.10,{ }^{* *} \mathrm{p}<0.05,{ }^{* * *} \mathrm{p}<0.01$.

Nessa subamostra regional, a expansão dos IFs também apresentou efeitos negativos sobre a empregabilidade das pessoas mais velhas: -0,87 p.p., significativo a 1\%. Também como nos resultados estimados para a amostra total, a expansão dos IFs teve efeito positivo sobre a formalização no mercado de trabalho das pessoas com 50 anos de idade ou mais e sobre a taxa de atividade das pessoas entre 18 e 29 anos.

Além disso, diferentemente da amostra com municípios do Norte e Nordeste, na amostra para o Centro-Sul do país há evidências de sinergia entre a criação de IFs e UFs para a empregabilidade das pessoas de 50 anos de idade, de modo que o efeito da criação dos IFs sobre a empregabilidade das pessoas mais velhas foi de um aumento médio de 0,09 p.p. $(-0,87+0,96)$.

A Tabela 5 traz as estimativas dos efeitos da criação dos campi de IFs e UFs em uma amostra de municípios com uma média de habitantes, entre 2000 e 2010, menor do que 100 mil. 
Tabela 5 - Efeito expansão dos IFs e UFs sobre o mercado de trabalho: diferença em diferenças ( $<100$ mil habitantes)

\begin{tabular}{|c|c|c|c|c|c|c|}
\hline \multirow[b]{2}{*}{ Var. Dep. } & \multicolumn{2}{|c|}{ Efeito IFs } & \multicolumn{2}{|c|}{ Efeito UFs } & \multicolumn{2}{|c|}{ Efeito interação } \\
\hline & (1) & (2) & (1) & (2) & (1) & (2) \\
\hline \multicolumn{7}{|c|}{18 ou mais anos de idade } \\
\hline \multirow[t]{2}{*}{ Empregado } & $0,6005^{*}$ & $-0,4265$ & $1,0536 * * *$ & 0,1865 & 0,4848 & 0,9701 \\
\hline & $(0,3064)$ & $(0,2933)$ & $(0,3639)$ & $(0,3650)$ & $(0,6617)$ & $(0,6118)$ \\
\hline \multirow[t]{2}{*}{ Formal } & $0,8147^{*}$ & 0,0913 & $-1,4208^{*}$ & $-1,0135$ & $2,5425^{* *}$ & 1,8629 \\
\hline & $(0,4890)$ & $(0,4339)$ & $(0,8403)$ & $(0,8199)$ & $(1,2041)$ & $(1,1768)$ \\
\hline \multirow[t]{2}{*}{ C_Própria } & $-0,0436$ & $-0,5561^{*}$ & 0,5816 & 0,5618 & $-0,0093$ & 0,0536 \\
\hline & $(0,2871)$ & $(0,2855)$ & $(0,4621)$ & $(0,4383)$ & $(0,7154)$ & $(0,7237)$ \\
\hline \multirow[t]{2}{*}{ Empregador } & $-0,1223^{* *}$ & $-0,0685$ & $-0,0740$ & $-0,0841$ & 0,0751 & 0,1001 \\
\hline & $(0,0502)$ & $(0,0491)$ & $(0,0661)$ & $(0,0657)$ & $(0,1315)$ & $(0,1243)$ \\
\hline \multirow[t]{2}{*}{$\begin{array}{l}\text { Taxa de } \\
\text { atividade }\end{array}$} & $-0,0380$ & $-0,0832$ & $-0,8552^{*}$ & $-0,3850$ & $2,1993 * *$ & $1,9520^{*}$ \\
\hline & $(0,3206)$ & $(0,3069)$ & $(0,5081)$ & $(0,4779)$ & $(0,9680)$ & $(1,0842)$ \\
\hline \multicolumn{7}{|c|}{18 a 29 anos de idade } \\
\hline \multirow[t]{2}{*}{ Empregado } & 0,6329 & $-0,2922$ & $1,4021 * * *$ & 0,5141 & 0,7693 & 1,3414 \\
\hline & $(0,4087)$ & $(0,4019)$ & $(0,4996)$ & $(0,4968)$ & $(1,0369)$ & $(0,9544)$ \\
\hline \multirow[t]{2}{*}{ Formal } & $1,7089^{* *}$ & 0,2986 & $-1,4112$ & $-1,1645$ & $3,5246 * *$ & $2,8740^{*}$ \\
\hline & $(0,6939)$ & $(0,6143)$ & $(0,9938)$ & $(0,9474)$ & $(1,5993)$ & $(1,5711)$ \\
\hline \multirow[t]{2}{*}{ C_Própria } & $-0,3950$ & $-0,3754$ & 0,3493 & 0,6271 & $-0,1634$ & $-0,2449$ \\
\hline & $(0,2652)$ & $(0,2671)$ & $(0,4331)$ & $(0,4213)$ & $(0,7220)$ & $(0,6991)$ \\
\hline \multirow[t]{2}{*}{ Empregador } & $-0,0275$ & $-0,0023$ & $-0,0559$ & $-0,0514$ & 0,0038 & 0,0160 \\
\hline & $(0,0439)$ & $(0,0444)$ & $(0,0474)$ & $(0,0497)$ & $(0,1027)$ & $(0,0990)$ \\
\hline \multirow[t]{2}{*}{$\begin{array}{l}\text { Taxa de } \\
\text { atividade }\end{array}$} & $-0,5478$ & $-0,0236$ & $-1,8236 * * *$ & $-0,7255$ & $2,5470 * *$ & 2,0006 \\
\hline & $(0,4553)$ & $(0,4402)$ & $(0,6192)$ & $(0,5595)$ & $(1,2788)$ & $(1,2839)$ \\
\hline \multicolumn{7}{|c|}{50 ou mais anos de idade } \\
\hline \multirow[t]{2}{*}{ Empregado } & 0,5125 & $-0,5934^{* *}$ & 0,3903 & $-0,3839$ & $1,2930^{*}$ & $1,6396^{* * *}$ \\
\hline & $(0,3145)$ & $(0,2961)$ & $(0,4117)$ & $(0,4011)$ & $(0,7455)$ & $(0,6640)$ \\
\hline \multirow[t]{2}{*}{ Formal } & $1,0831^{*}$ & 0,5563 & 0,0715 & 0,2347 & 1,5718 & 1,2265 \\
\hline & $(0,5562)$ & $(0,5365)$ & $(0,7331)$ & $(0,7152)$ & $(1,5276)$ & $(1,5208)$ \\
\hline \multirow[t]{2}{*}{ C_Própria } & 0,3985 & $-0,6420^{*}$ & 0,5209 & 0,1591 & 0,1451 & 0,4725 \\
\hline & $(0,3661)$ & $(0,3464)$ & $(0,4959)$ & $(0,4798)$ & $(0,7917)$ & $(0,7889)$ \\
\hline Empregador & 0,0306 & 0,0521 & $-0,1130$ & $-0,1373$ & 0,1510 & 0,1795 \\
\hline
\end{tabular}


conclusão.

\begin{tabular}{|c|c|c|c|c|c|c|}
\hline \multirow[b]{2}{*}{ Var. Dep. } & \multicolumn{2}{|c|}{ Efeito IFs } & \multicolumn{2}{|c|}{ Efeito UFs } & \multicolumn{2}{|c|}{ Efeito interação } \\
\hline & (1) & (2) & (1) & (2) & (1) & (2) \\
\hline \multicolumn{7}{|c|}{50 ou mais anos de idade } \\
\hline \multirow{3}{*}{$\begin{array}{l}\text { Taxa de } \\
\text { atividade }\end{array}$} & $(0,0626)$ & $(0,0638)$ & $(0,0935)$ & $(0,0943)$ & $(0,2010)$ & $(0,1915)$ \\
\hline & $1,4481 * * *$ & 0,3088 & 0,2540 & $-0,0538$ & 0,3123 & 0,7343 \\
\hline & $(0,4477)$ & $(0,3875)$ & $(0,5434)$ & $(0,5142)$ & $(1,2418)$ & $(1,2753)$ \\
\hline $\begin{array}{l}\text { Dummy de } \\
\text { ano }\end{array}$ & Sim & Sim & Sim & Sim & Sim & Sim \\
\hline Controles (A) & Sim & Sim & Sim & Sim & Sim & Sim \\
\hline Controles (B) & Não & Sim & Não & Sim & Não & Sim \\
\hline Observações & 10.522 & 10.522 & 10.522 & 10.522 & 10.522 & 10.522 \\
\hline
\end{tabular}

Fonte: Elaboração própria.

Nota: Controles (A): proporção de homens do município, proporção de brancos, proporções de pessoas de 15 a 24 anos, de 25 a 59 anos, de 60 ou mais anos de idade e proporção de pessoas residentes em domicílios localizados na zona urbana; Controles (B): o nível, em 2000, da proporção de homens do município, da proporção de brancos, das proporções de pessoas de 15 a 24 anos, de 25 a 59 anos, de 60 ou mais anos de idade, da proporção de pessoas residentes em domicílios localizados na zona urbana e do PIB per capita; Desvios padrão entre parênteses; Níveis de significância: ${ }^{*} \mathrm{p}<0.10,{ }^{* *} \mathrm{p}<0.05,{ }^{* * *} \mathrm{p}<0.01$.

Primeiramente, entre as pessoas com 18 ou mais anos de idade, observa-se sinergia positiva na taxa de atividade (1,95 p.p., significativo a 10\%). No grupo etário das pessoas de 18 a 29 anos de idade na amostra dos municípios com menos de 100 mil habitantes, no modelo com todos os controles, há evidências de sinergia positiva sobre a formalização: 2,87 p.p., significativo a $10 \%$.

Já sobre o grupo de 50 ou mais anos de idade, foram encontrados efeitos negativos da criação dos IFs sobre a ocupação (-0,59 p.p., significativo a 5\%) e inserção no mercado de trabalho por conta própria (-0,64 p.p., significativo a 10\%). Por outro lado, há sinergias positivas na ocupação (1,64 p.p., significativo a 5\%).

Por fim, a Tabela 6 apresenta as estimativas da equação 1 com o uso da amostra de municípios com população média entre 2000 e 2010 menor do que 50 mil habitantes. 
Tabela 6 - Efeito expansão dos IFs e UFs sobre o mercado de trabalho: diferença em diferenças ( $<50$ mil habitantes)

\begin{tabular}{|c|c|c|c|c|c|c|}
\hline \multirow[b]{2}{*}{ Var. Dep. } & \multicolumn{2}{|c|}{ Efeito IFs } & \multicolumn{2}{|c|}{ Efeito UFs } & \multicolumn{2}{|c|}{ Efeito interação } \\
\hline & (1) & (2) & (1) & (2) & (1) & (2) \\
\hline \multicolumn{7}{|c|}{18 ou mais anos de idade } \\
\hline \multirow[t]{2}{*}{ Empregado } & $1,0006^{* *}$ & 0,4689 & $1,6658^{* * *}$ & 0,7772 & $-0,2281$ & 0,4689 \\
\hline & $(0,4382)$ & $(1,3350)$ & $(0,5246)$ & $(0,5291)$ & $(1,6485)$ & $(1,3350)$ \\
\hline \multirow[t]{2}{*}{ Formal } & 0,6084 & $-0,3327$ & $-2,9257^{* * *}$ & $-2,5208 * * *$ & $3,5761 * *$ & $3,5342 * *$ \\
\hline & $(0,6940)$ & $(0,5464)$ & $(0,8811)$ & $(0,8578)$ & $(1,6284)$ & $(1,6626)$ \\
\hline \multirow[t]{2}{*}{ C_Própria } & $-0,1504$ & $-0,6454$ & $1,4467^{* * *}$ & $1,0100^{* *}$ & 0,3485 & 1,1897 \\
\hline & $(0,4975)$ & $(0,4975)$ & $(0,4495)$ & $(0,4722)$ & $(0,9687)$ & $(0,8752)$ \\
\hline \multirow[t]{2}{*}{ Empregador } & $-0,0800$ & 0,0008 & 0,0167 & 0,0106 & $-0,0643$ & $-0,0823$ \\
\hline & $(0,0841)$ & $(0,0791)$ & $(0,1036)$ & $(0,1015)$ & $(0,3112)$ & $(0,3064)$ \\
\hline \multirow[t]{2}{*}{$\begin{array}{l}\text { Taxa de } \\
\text { atividade }\end{array}$} & $-0,1277$ & $-0,1052$ & $-0,7189$ & $-0,7291$ & $2,3182 * *$ & $2,8885 * *$ \\
\hline & $(0,5404)$ & $(0,4873)$ & $(0,6707)$ & $(0,6646)$ & $(1,0275)$ & $(1,1072)$ \\
\hline \multicolumn{7}{|c|}{18 a 29 anos de idade } \\
\hline \multirow[t]{2}{*}{ Empregado } & $1,3646^{* *}$ & 0,7436 & $2,1133^{* * *}$ & 1,1632 & $-1,7178$ & $-0,9337$ \\
\hline & $(0,6571)$ & $(0,6585)$ & $(0,7481)$ & $(0,7610)$ & $(2,1342)$ & $(1,8204)$ \\
\hline \multirow[t]{2}{*}{ Formal } & 1,5310 & $-0,2132$ & $-4,1595 * * *$ & $-4,0287 * * *$ & $5,5873 * *$ & $6,0315^{* *}$ \\
\hline & $(1,1390)$ & $(0,9108)$ & $(1,1150)$ & $(1,0378)$ & $(2,7733)$ & $(2,4846)$ \\
\hline \multirow[t]{2}{*}{ C_Própria } & $-0,7303$ & $-0,6841$ & $1,1156^{* *}$ & $1,0613^{* *}$ & 0,2262 & 0,6520 \\
\hline & $(0,4704)$ & $(0,4773)$ & $(0,4569)$ & $(0,4406)$ & $(0,9493)$ & $(1,0175)$ \\
\hline \multirow[t]{2}{*}{ Empregador } & $-0,0741$ & $-0,0465$ & $-0,1829^{* *}$ & $-0,1884^{* *}$ & 0,2309 & 0,2360 \\
\hline & $(0,0745)$ & $(0,0733)$ & $(0,0814)$ & $(0,0842)$ & $(0,1862)$ & $(0,1940)$ \\
\hline \multirow[t]{2}{*}{$\begin{array}{l}\text { Taxa de } \\
\text { atividade }\end{array}$} & $-0,6805$ & $-0,1403$ & $-2,7028 * * *$ & $-2,2072 * * *$ & $4,4700 * * *$ & $4,7788 * * *$ \\
\hline & $(0,8093)$ & $(0,7052)$ & $(0,8436)$ & $(0,7903)$ & $(1,4814)$ & $(1,2199)$ \\
\hline \multicolumn{7}{|c|}{50 ou mais anos de idade } \\
\hline \multirow[t]{2}{*}{ Empregado } & 0,3323 & $-0,5953$ & 0,9474 & 0,2372 & 2,2196 & $2,8335^{* *}$ \\
\hline & $(0,4201)$ & $(0,4292)$ & $(0,5761)$ & $(0,5554)$ & $(1,7839)$ & $(1,4441)$ \\
\hline \multirow[t]{2}{*}{ Formal } & 1,3767 & 0,8118 & 0,3117 & 0,4229 & $-2,5923$ & $-2,5650$ \\
\hline & $(0,8630)$ & $(0,7808)$ & $(1,0722)$ & $(1,0280)$ & $(3,2092)$ & $(3,4035)$ \\
\hline \multirow[t]{2}{*}{ C_Própria } & 0,4669 & $-0,4744$ & $1,1736^{* *}$ & 0,2427 & 0,3613 & $1,7952^{*}$ \\
\hline & $(0,6029)$ & $(0,6219)$ & $(0,5889)$ & $(0,5747)$ & $(1,2682)$ & $(1,0636)$ \\
\hline \multirow[t]{2}{*}{ Empregador } & 0,0268 & 0,0880 & 0,0180 & $-0,0244$ & 0,2806 & 0,3018 \\
\hline & $(0,1052)$ & $(0,1043)$ & $(0,1619)$ & $(0,1609)$ & $(0,5525)$ & $(0,5215)$ \\
\hline
\end{tabular}

continua... 
conclusão.

\begin{tabular}{|c|c|c|c|c|c|c|}
\hline \multirow[b]{2}{*}{ Var. Dep. } & \multicolumn{2}{|c|}{ Efeito IFs } & \multicolumn{2}{|c|}{ Efeito UFs } & \multicolumn{2}{|c|}{ Efeito interação } \\
\hline & (1) & (2) & (1) & (2) & (1) & (2) \\
\hline \multicolumn{7}{|c|}{50 ou mais anos de idade } \\
\hline \multirow[t]{2}{*}{$\begin{array}{l}\text { Taxa de } \\
\text { atividade }\end{array}$} & $1,1223^{*}$ & 0,2602 & 0,7570 & $-0,3545$ & $-1,0632$ & 0,7656 \\
\hline & $(0,6717)$ & $(0,6429)$ & $(0,7456)$ & $(0,6541)$ & $(2,1871)$ & $(2,1245)$ \\
\hline Dummy de ano & Sim & Sim & Sim & Sim & Sim & Sim \\
\hline Controles (A) & Sim & $\operatorname{Sim}$ & Sim & Sim & $\operatorname{Sim}$ & Sim \\
\hline Controles (B) & Não & Sim & Não & Sim & Não & Sim \\
\hline Observações & 9.880 & 9.880 & 9.880 & 9.880 & 9.880 & 9.880 \\
\hline
\end{tabular}

Fonte: Elaboração própria.

Nota: Controles (A): proporção de homens do município, proporção de brancos, proporções de pessoas de 15 a 24 anos, de 25 a 59 anos, de 60 ou mais anos de idade e proporção de pessoas residentes em domicílios localizados na zona urbana; Controles (B): o nível, em 2000, da proporção de homens do município, da proporção de brancos, das proporções de pessoas de 15 a 24 anos, de 25 a 59 anos, de 60 ou mais anos de idade, da proporção de pessoas residentes em domicílios localizados na zona urbana e do PIB per capita; Desvios padrão entre parênteses; Níveis de significância: ${ }^{*} \mathrm{p}<0.10,{ }^{* *} \mathrm{p}<0.05$, *** $\mathrm{p}<0.01$.

Percebe-se que há mais coeficientes estimados significativos do que nas amostras anteriores. Na população com 18 anos ou mais, destaca-se o efeito sinérgico positivo encontrado sobre a formalização. $\mathrm{O}$ efeito positivo estimado nos municípios com expansão de IFs, dado que houve expansão de UFs, foi de 3,5 p.p., enquanto o efeito da expansão de UFs, dado que houve também expansão de IFs, foi de pouco mais de 1,0 p.p. (3,5342-2,5208).

Resultados semelhantes, mas com impactos mais intensos, foram encontrados para a população entre 18 e 29 anos de idade. Além de efeitos sinérgicos positivos sobre a formalização, observaram-se efeitos positivos da expansão de UFs na inserção por conta própria no mercado de trabalho e sinergia positiva na taxa de atividade. Contudo, também se verificou impacto negativo sobre a taxa de empregadores: -0,18 p.p., significativo a $5 \%$.

Para a população com mais de 50 anos de idade, embora não tenham sido encontrados efeitos isolados da criação de IFs e UFs, constataram-se sinergias positivas da criação de ambos no que tange à ocupação (2,83 p.p., significativo a 5\%) e à inserção no mercado de trabalho por conta própria (1,79 p.p., significativo a 10\%).

Em resumo, os resultados econométricos apontam que: a) as evidências de sinergia da expansão de IFs e UFs estão principalmente sobre a taxa de ocupação e a taxa de formalização; b) a sinergia sobre a empregabilidade (taxa de ocupação) se manifesta, preferencialmente, ou mais forte, sobre as pessoas com 50 ou mais anos de idade nos municípios menores; c) já a sinergia sobre a formalização da mão de obra incide sobre os indivíduos mais jovens (18 a 29 anos), mas também 
nos municípios menores; e d) os efeitos sinérgicos sobre a formalização das pessoas mais jovens são os de maior intensidade.

As evidências que apontam para maiores efeitos em municípios menores encontram respaldo no fato de que a expansão da educação federal foi direcionada ao interior do país, conforme já discutido. Além disso, para o geral, quando confrontam-se as estimativas obtidas nesta pesquisa com os resultados da literatura, encontram-se sinais de convergências com os resultados destacados por Beeson e Montgomery (1993), para o Estados Unidos, e Li e Xing (2010) para a China. Os efeitos positivos no mercado de trabalho oferecem também um mecanismo capaz de explicar o efeito positivo observado sobre a renda dos municípios nos trabalhos de Vinhais (2013) e Niquito, Ribeiro e Portugal (2018). Há também consonância com as estimativas positivas da pesquisa de Caldarelli, Camara e Perdigão (2015), a qual encontrou que a expansão universitária, no interior do Paraná, aumentou indicadores de emprego e renda.

O efeito mais forte nos municípios menores pode também estar indicando que a instalação de IFs e UFs, ao ampliar as oportunidades de acumulação de capital humano específico e geral, pode dar dinamismo ao mercado de trabalho das economias locais.

Outro resultado que merece destaque é que, dentre os municípios com até 50 mil habitantes, a instalação de UFs impactou positivamente a inserção dos indivíduos no mercado de trabalho via trabalho por conta própria (exceto entre as pessoas com 50 ou mais anos de idade). Esse efeito vai ao encontro da redução da inserção dessa faixa etária no mercado de trabalho formal, que, embora fraco, pode estar indicando uma possível redução da oferta de trabalho dos jovens no mercado formal e um aumento no trabalho por conta própria.

Vale ainda comentar que a expansão isolada (desconsiderando a expansão conjunta) apresenta alguns impactos negativos sobre as medidas de mercado de trabalho (boa parte desses efeitos são suavizados diante da interação da expansão). Contudo, isso pode estar relevando uma maior alocação de tempo na acumulação de capital humano proporcionada pela própria expansão da rede federal de ensino.

\subsection{Efeitos de Curto Prazo}

Como mencionado em Florax (1994) e Vinhais (2013), a expansão da rede de educação pode ter impactos de curto e de longo prazo. Os de curto prazo estariam associados ao choque que a instalação de um campus de IF ou/e UF pode gerar em uma economia local. Tal choque pode acarretar uma variação de renda e de demanda que desencadearia efeitos de equilíbrio geral sobre a economia. Por sua vez, os efeitos de longo prazo seriam aqueles associados ao aumento do capital humano da região e à melhoria nos demais indicadores de desenvolvimento humano. 
Nesta etapa do trabalho, propõe-se a realização de um exercício econométrico simples para tentar se ter uma ideia do quão forte foi o efeito de curto prazo da expansão dos IFs e UFs sobre o mercado de trabalho. Como visto anteriormente, há principalmente importantes efeitos sobre a empregabilidade e a formalização da mão de obra. Assim, estima-se o mesmo modelo apresentado na equação 1 tendo como variável dependente a participação do emprego nos setores de comércio, serviços e construção civil no total do emprego em todos os setores dos municípios.

Esses três setores são aqueles que possivelmente mais acomodariam os efeitos de curto prazo levantados na literatura. A contratação de docentes e técnico-administrativos, por exemplo, aumentaria a demanda por bens e serviços nas economias locais, exercendo uma variação no gasto total das famílias (principalmente nos municípios menores) em direção aos setores de comércio e serviços. Por sua vez, a instalação e/ou construção de campi aqueceria o mercado da construção civil. Nesse setor, o aumento da demanda por residências (em função da chegada de professores, técnico-administrativos e estudantes) também poderia desencadear algum efeito.

A hipótese que sustenta esse exercício é que, caso os efeitos de curto prazo sejam fortes, a participação do comércio, serviços e construção civil na empregabilidade do mercado de trabalho deve ter aumentando em função da expansão da rede educação federal.

Tabela 7 - Efeito expansão IFs e UFs sobre a participação no emprego do agregado dos setores de comércio, serviços e construção civil

\begin{tabular}{|c|c|c|c|c|c|c|c|}
\hline \multirow{3}{*}{$\begin{array}{l}\text { Grupos } \\
\text { etários }\end{array}$} & \multicolumn{2}{|c|}{ Efeito IFs } & \multicolumn{2}{|c|}{ Efeito UFs } & \multicolumn{2}{|c|}{ Efeito interação } & \multirow[b]{2}{*}{ Observações } \\
\hline & (1) & (2) & (1) & (2) & (1) & (2) & \\
\hline & \multicolumn{6}{|c|}{ Amostra completa } & \\
\hline \multirow[t]{2}{*}{18 ou mais } & $-0,7149$ & $-0,1720$ & 0,0807 & 0,3869 & $-0,1605$ & $-0,3580$ & 11.014 \\
\hline & $(0,6010)$ & $(0,4376)$ & $(0,5863)$ & $(0,4642)$ & $(1,0089)$ & $(0,8481)$ & \\
\hline \multirow[t]{2}{*}{18 a 29} & $-0,5986$ & $-0,1120$ & $-0,3905$ & $-0,1066$ & 0,4239 & 0,1242 & 11.014 \\
\hline & $(0,6502)$ & $(0,4880)$ & $(0,8579)$ & $(0,7843)$ & $(1,2412)$ & $(1,1270)$ & \\
\hline \multirow[t]{2}{*}{50 ou mais } & $-0,1675$ & $0,7981^{*}$ & 1,2997 & $1,8475^{* *}$ & $-2,3495^{*}$ & $-2,4430 * *$ & 11.014 \\
\hline & $(0,7106)$ & $(0,4714)$ & $(0,9945)$ & $(0,7792)$ & $(1,3237)$ & $(1,1048)$ & \\
\hline \multicolumn{8}{|c|}{ Apenas Norte e Nordeste } \\
\hline \multirow[t]{2}{*}{18 ou mais } & $-0,0161$ & $0,9911^{*}$ & 1,2012 & $2,1096 * * *$ & $-3,1638$ & $-2,1877$ & 4.472 \\
\hline & $(0,7887)$ & $(0,5739)$ & $(0,8071)$ & $(0,6661)$ & $(3,2044)$ & $(2,2416)$ & \\
\hline \multirow[t]{2}{*}{18 a 29} & 0,6476 & $1,4064^{*}$ & 1,5281 & $2,0724^{* *}$ & $-3,2080$ & $-2,6764$ & 4.472 \\
\hline & $(0,8600)$ & $(0,7300)$ & $(0,9839)$ & $(0,9152)$ & $(3,1417)$ & $(2,6801)$ & \\
\hline \multirow[t]{2}{*}{50 ou mais } & 1,6078 & $2,7682 * * *$ & $4,1149 * * *$ & $4,9650 * * *$ & $-7,6875^{* *}$ & $-6,8192 * *$ & 4.472 \\
\hline & $(1,1073)$ & $(0,8625)$ & $(1,0368)$ & $(0,9704)$ & $(3,7227)$ & $(2,9227)$ & \\
\hline \multicolumn{8}{|c|}{ Apenas Sudeste, Sul e Centro-Oeste } \\
\hline \multirow[t]{2}{*}{18 ou mais } & $-1,1905$ & $-0,8118$ & $-0,9866$ & $-0,6290$ & 1,6419 & 1,1942 & 6.542 \\
\hline & $(0,7915)$ & $(0,5458)$ & $(0,7551)$ & $(0,6528)$ & $(1,1456)$ & $(0,9813)$ & \\
\hline 18 a 29 & $-1,4289^{*}$ & $-1,0443^{*}$ & $-1,8675$ & $-1,3570$ & $2,7680^{*}$ & 2,1541 & 6.542 \\
\hline
\end{tabular}


conclusão.

\begin{tabular}{|c|c|c|c|c|c|c|c|}
\hline \multirow{2}{*}{$\begin{array}{l}\text { Grupos } \\
\text { etários }\end{array}$} & \multicolumn{2}{|c|}{ Efeito IFs } & \multicolumn{2}{|c|}{ Efeito UFs } & \multicolumn{2}{|c|}{ Efeito interação } & \multirow[b]{2}{*}{ Observações } \\
\hline & (1) & (2) & (1) & (2) & (1) & (2) & \\
\hline \multicolumn{8}{|c|}{ Apenas Sudeste, Sul e Centro-Oeste } \\
\hline \multirow{3}{*}{50 ou mais } & $(0,8340)$ & $(0,6157)$ & $(1,2411)$ & $(1,1257)$ & $(1,5470)$ & $(1,3951)$ & \\
\hline & $-0,9865$ & $-0,1934$ & $-1,1623$ & $-0,5242$ & 1,4579 & 1,0216 & 6.542 \\
\hline & $(0,7266)$ & $(0,4914)$ & $(0,9178)$ & $(0,6878)$ & $(1,2446)$ & $(1,0489)$ & \\
\hline \multicolumn{8}{|c|}{ Apenas municípios com até 100 mil habitantes } \\
\hline \multirow[t]{2}{*}{18 ou mais } & $-0,1036$ & $0,8237^{*}$ & 0,1590 & 0,6802 & 0,1478 & $-0,1457$ & 10.522 \\
\hline & $(0,4928)$ & $(0,4779)$ & $(0,7302)$ & $(0,6524)$ & $(1,6192)$ & $(1,3173)$ & \\
\hline \multirow[t]{2}{*}{18 a 29} & 0,6698 & $1,1445^{*}$ & 0,6584 & 0,9617 & 0,0034 & $-0,1566$ & 10.522 \\
\hline & $(0,6479)$ & $(0,6535)$ & $(0,8161)$ & $(0,7438)$ & $(1,7457)$ & $(1,5490)$ & \\
\hline \multirow[t]{2}{*}{50 ou mais } & $-0,5804$ & 0,5457 & $2,2355^{* *}$ & $2,8634 * * *$ & $-1,8422$ & $-2,1421$ & 10.522 \\
\hline & $(0,7142)$ & $(0,6823)$ & $(0,9151)$ & $(0,9043)$ & $(1,8330)$ & $(1,6933)$ & \\
\hline \multicolumn{8}{|c|}{ Apenas municípios com até 50 mil habitantes } \\
\hline \multirow[t]{2}{*}{18 ou mais } & 0,0962 & 0,8351 & 0,1064 & 1,0665 & $-0,6916$ & $-1,7397$ & 9.880 \\
\hline & $(0,7525)$ & $(0,7320)$ & $(0,9672)$ & $(0,8314)$ & $(2,9834)$ & $(2,6713)$ & \\
\hline \multirow[t]{2}{*}{18 a 29} & 0,3835 & 0,7272 & 1,2747 & 1,8098 & 1,4600 & 0,8884 & 9.880 \\
\hline & $(0,9650)$ & $(0,9757)$ & $(1,1814)$ & $(1,1224)$ & $(3,3397)$ & $(3,1679)$ & \\
\hline \multirow[t]{2}{*}{50 ou mais } & $-0,0468$ & 0,6927 & 1,8971 & $2,8394^{* *}$ & $-7,7480 * * *$ & $-8,7160 * * *$ & 9.880 \\
\hline & $(1,0014)$ & $(0,9494)$ & $(1,4835)$ & $(1,4469)$ & $(2,3594)$ & $(2,2363)$ & \\
\hline $\begin{array}{l}\text { Dummy } \\
\text { de ano }\end{array}$ & Sim & Sim & Sim & Sim & Sim & Sim & \\
\hline $\begin{array}{l}\text { Controle } \\
\text { (A) }\end{array}$ & Sim & Sim & Sim & Sim & Sim & Sim & \\
\hline $\begin{array}{l}\text { Controle } \\
\text { (B) }\end{array}$ & Não & Sim & Não & Sim & Não & Sim & \\
\hline
\end{tabular}

Fonte: Elaboração própria.

Nota: Controles (A): proporção de homens do município, proporção de brancos, proporções de pessoas de 15 a 24 anos, de 25 a 59 anos, de 60 ou mais anos de idade e proporção de pessoas residentes em domicílios localizados na zona urbana; controles (B): o nível, em 2000, da proporção de homens do município, da proporção de brancos, das proporções de pessoas de 15 a 24 anos, de 25 a 59 anos, de 60 ou mais anos de idade, da proporção de pessoas residentes em domicílios localizados na zona urbana e do PIB per capita; Desvios padrão entre parênteses; Níveis de significância: ${ }^{*} \mathrm{p}<0.10,{ }^{* *} \mathrm{p}<0.05,{ }^{* * *} \mathrm{p}<0.01$.

A análise dos resultados expostos na Tabela 7 sugerem que os efeitos de curto prazo não são muito fortes. Essa conclusão sai da pouca significância estatística observada na maior parte das estimativas. Em termos de efeitos sinérgicos, não há evidências de efeitos positivos. A única exceção, em relação a coeficientes estatisticamente significativos, fica por conta do efeito da expansão das UFs sobre as pessoas com 50 ou mais anos de idade, visto que na maior parte das especificações estimadas há indícios de que tenha aumentado o emprego desse grupo nos setores de comércio, serviços e construção civil. 
No entanto, a baixa incidência de estimativas significativas para o geral das estimações no exercício de checagem do papel dos efeitos de curto prazo reforça a hipótese de que os principais resultados observados sejam consequência da acumulação de capital humano específico e geral. Esse é um resultado importante para a política de expansão da rede federal de educação. Óbvio que efeitos de curto prazo seriam desejáveis também, no entanto, no caso de uma política de educação, tais efeitos são apenas colaterais. O foco central da política está na melhoria das condições efetivas do mercado de trabalho em função da maior e melhor educação.

Embora todos esses efeitos sejam interessantes, é importante frisar que esta é uma primeira tentativa de se avaliar os impactos da expansão das UFs e dos IFs no mercado de trabalho dos municípios contemplados por esses importantes investimentos no país. Mais do que isso, é uma avaliação com uma técnica não experimental. Recomenda-se tanto a realização de outras avaliações com outras técnicas e dados, quanto o uso de estudos de casos mais aprofundados nos impactos sobre os municípios pequenos, principalmente estudos que possam auxiliar na identificação e entendimento dos canais que geram os efeitos e criam as sinergias observadas, além de isolar melhor os efeitos associados a cada investimento.

\section{Considerações Finais}

Este estudo teve como objetivo verificar o impacto da expansão da rede federal de educação superior sobre alguns indicadores importantes do mercado de trabalho, como as taxas de ocupação e de atividade, o nível de formalização da mão de obra e medidas de empreendedorismo, algo inédito na literatura do assunto. $\mathrm{O}$ estudo também visou inovar ao explorar os efeitos da expansão de toda a rede, institutos e universidades federais, e não apenas de uma parte dela (universidades federais). Neste trabalho também foi explorada a possibilidade de potencialização dos efeitos entre IFs e UFs.

Em resumo, há evidências de sinergia entre a criação de campi de IFs e de UFs, principalmente sobre a taxa de ocupação e a taxa de formalidade. Os efeitos, quando significativos, parecem em geral mais fortes em municípios menores e entre os indivíduos mais jovens. Esses resultados são interessantes em termos de políticas públicas, uma vez que a promoção do aumento de postos de trabalhos auxilia diretamente um grupo etário que possui maiores obstáculos para participar do mercado de trabalho (principalmente em regiões com menores oportunidades, como é o caso dos municípios pequenos). Os resultados casam especificamente com as duas últimas fases de expansão das UFs e IFs, já que nessas fases as instituições de ensino federal ganharam maior intensidade no interior do país.

É importante mencionar que a análise econométrica complementar apontou

que os efeitos de curto prazo não parecem ser a principal razão que explicaria os 
efeitos estimados. Há pistas de que a acumulação de capital humano (com todos os seus benefícios, como ganhos de produtividade) está por trás dos efeitos observados. Sem dúvidas, esse é um tema para futuros desdobramentos da pesquisa no tema.

Ainda dentro do contexto de questões em aberto que esta pesquisa levanta, destacam-se as seguintes: qual o ganho de capital humano para os municípios do interior do país? Como se dão os efeitos heterogêneos em função de sexo e etnia das pessoas? Existe alguma combinação de cursos dos IFs e das UFs que potencializam tais sinergias? Recomendam-se, também, estudos de casos em municípios pequenos, pois seria mais fácil para realizar a identificação e o entendimento dos canais que geraram os efeitos.

Por fim, dentro do pacote de recomendações para futuras pesquisas, está a realização de mais estudos com objetivos similares, mas com outras técnicas e bases de dados. A formação de consenso a respeito de efeitos de políticas públicas, principalmente quando não há a possibilidade de fases prévias de experimentação, requer a realização de diversas pesquisas não experimentais para a ampliação da confiança acerca da magnitude dos efeitos estimados. Desse modo, técnicas de avaliação ex ante, como a utilização de modelos de equilíbrio geral computável, também são instrumentais com grande capacidade de colaboração no processo de avaliação de impacto de política públicas.

Entre 2000 e 2010, foi extremamente baixa a proporção de municípios do total que receberam concomitantemente a expansão de IFs e UFs (apenas $0.5 \%$ do total dos municípios do país). Caso a realização de mais estudos também aponte para evidências positivas de sinergias, a recomendação de política pública para futuras expansões, quando economicamente viável novamente, é que os esforços sejam direcionados aos municípios que já foram contemplados com outra instituição.

\section{Referências}

AGHION, P.; HOWITT, P. A model of growth through creative destruction. Econometrica, v. 60, n. 2, p. 323-351, 1992.

ANDRADE, A. F. B. Os institutos federais de educação, ciência e tecnologia: uma análise de sua institucionalidade. Tese (Doutorado) - Faculdade de Educação, Universidade de Braslia, 2014.

BEESON, P.; MONTGOMERY, E. The effects of colleges and universities on local labor markets. The Review of Economics and Statistics, v. 75, n. 4, p. 753-761, 1993.

BERTRAND, M.; DUFLO, E.; MULLAINATHAN, S. How much should we trust differencesin-differences estimates? The Quarterly Journal of Economics, v. 119, n. 1, p. 249-275, 2004.

BRASIL. Decreto $n^{\circ}$ 6.096, de 24 de abril de 2007. Institui o Programa de Apoio a Planos de Reestruturação e Expansão das Universidades Federais - REUNI. Brasilia, DF: Presidência da República, 2007. Disponível em: http://www.planalto.gov.br/ccivil_03/_ato2007-2010/2007/ decreto/d6096.htm. Acesso em 6 jul. 2020. 
BRASIL. Lei 11.892 de 29 de dezembro de 2008. Institui a Rede Federal de Educação Profissional, Científica e Tecnológica, cria os Institutos Federais de Educação, Ciência e Tecnologia, e dá outras providências. Brasília, DF: Presidência da República, 2008. Disponível em: http:// www.planalto.gov.br/ccivil_03/_Ato2007-2010/2008/Lei/L11892.htm. Acesso em: 6 jul. 2020.

BRASIL. Ministério da Educação. Análise sobre a expansão das universidades federais 2003 a 2012: relatório da Comissão Constituída pela Portaria no 126/2012. Brasília: MEC, 2012a. Disponível em: http://portal.mec.gov.br/index.php?option=com_docmanEtask=doc_ downloadEgid =12386EItemid $=$. Acesso em: 24 jul. 2015.

BRASIL. Ministério da Educação. Instituto Nacional de Estudos e Pesquisas Educacionais (Inep). Sinopses Estatísticas da Educação Superior (2000 a 2010). Brasília: Inep, 2015. Disponível em: http://portal.inep.gov.br/web/guest/sinopses-estatisticas-da-educacao-superior. Acesso em: 6 jul. 2020.

BRASIL. Ministério da Educação. Instituto Nacional de Estudos e Pesquisas Educacionais (Inep). Censo da educação superior: 2010: resumo técnico. Brasília: Inep, 2012b. Disponível em: http://download.inep.gov.br/download/superior/censo/2010/resumo_tecnico_censo_ educacao_superior_2010.pdf. Acesso em: 6 jul. 2020.

BRASIL. Senado Federal. Portal do orçamento: orçamento anual. Brasília, [2019a].

BRASIL. Sistema integrado de monitoramento, execução e controle do Ministério da Educação: módulo público. Brasília, [2019b].

CALDARELLI, C. E.; CAMARA, M. R. G.; PERDIGÃO, C. Instituições de ensino superior e desenvolvimento econômico: o caso das universidades estaduais paranaenses. Planejamento e Políticas Públicas, n. 44, p. 85-112, 2015.

CARDOSO JR., J. De volta para o futuro? As fontes de recuperação do emprego formal no brasil e as condições para sua sustentabilidade temporal. Texto para Discussão - IPEA, n. 1310, 2007.

CARNOY, M.; LOYALKA, P.; FROUMIN, I. University expansion in the BRIC countries and the global information economy. Change: The Magazine of Higher Learning, v. 45, n. 4, p. 36-43, 2013.

CASTELLANI, F.; LORA, E. Is entrepreneurship a channel of social mobility in Latin America? Latin American Journal of Economics, v. 51, n. 2, p. 179-194, 2014.

CHIARINI, T.; VIEIRA, K. P.; ZORZIN, P. L. G. Universidades federais mineiras: análise da produção de pesquisa científica e conhecimento no contexto do sistema mineiro de inovação. Nova Economia, v. 22, n. 2, p. 307-332, 2012.

CORSEUIL, C. H. et al. A rotatividade dos jovens no mercado de trabalho formal brasileiro. In: CORSEUIL, C. H.; BOTELHO, R. U. (org.). Desafios à trajetória profissional dos jovens brasileiros. Rio de Janeiro: Ipea, 2014.

CURI, A. Z.; MENEZES-FILHO, N. A. Os determinantes das transições ocupacionais no mercado de trabalho brasileiro. In: ENCONTRO NACIONAL DA ANPEC, 32., 2004, João Pessoa. Anais [...] João Pessoa: ANPEC, 2004. 
FLORAX, R. J. G. M. The university: a regional booster? Economic impacts of academic knowledge infrastructure. Aldershot: Avebury, 1994.

GARCIA, F.; HELFAND, S. M.; SOUZA, A. P. Transferencias monetarias condicionadas y políticas de desarrollo rural en Brasil: posibles sinergias entre Bolsa Familia y el Pronaf. In: MALDONADO, J. H. et al. Protección, producción, promoción: explorando sinergias entre protección social y fomento productivo rural en América Latina. Bogotá: Universidad de los Andes, 2016.

GODDARD, J. B.; CHATTERTON, P. Regional development agencies and the knowledge economy: harnessing the potential of universities. Environment and Planning C: Politics and Space - SAGE Journals, v. 17, n. 6, p. 685-699, 1999.

GONTIJO, B. A.; AMARAL, E. F. L. Associação do ensino profissionalizante com rendimento e emprego: Minas Gerais (2009 e 2011). Planejamento e Políticas Públicas, n. 44, p. 113-144, 2015.

KHANDKER, S. R.; KOOLWAL, G. B.; SAMAD, H. A. Handbook on impact evaluation: quantitative methods and practices. Washington: World Bank Publications, 2009.

LI, S.; XING, C. China's Higher Education Expansion and its Labor Market Consequences. IZA Discussion Papers, n. 4974, 2010.

MORETTI, E. Estimating the social return to higher education: evidence from longitudinal and repeated cross-sectional data. Journal of Econometrics, v. 121, n. 1-2, p. 175-212, 2004.

MOWERY, D. C. Universities in national innovation systems. Georgia Institute of Technology, 2005.

NERI, M. C. Decent work and the informal sector in Brazil. EPGE Working Papers Series, n. $461,2002$.

NIQUITO, T.; RIBEIRO, F. G.; PORTUGAL, M. S. Impacto da criação das novas universidades federais sobre as economias locais. Planejamento e Políticas Públicas, n. 51, p. 367-394, 2018.

OLIVA, B. T.; RIBEIRO, F. G.; SOUZA, A. O retorno da educação profissional no mercado de trabalho: evidências a partir de dados longitudinais. São Paulo School of Economics Working Paper, n. 3, 2015.

PARKER, S. C. The economics of entrepreneurship. 2nd ed. Cambridge: Cambridge University Press, 2018.

PIOPIUNIK, M.; RYAN, P. Improving the transition between education/training and the labour market: what can we learn from various national approaches? EENEE Analytical Report, v. 13, p. 1-69, 2012.

RAMOS, L. O desempenho recente do mercado de trabalho brasileiro: tendências, fatos estilizados e padrões espaciais. IPEA Texto para Discussão, n. 1255, 2007.

REIS, M.; ULYSSEA, G. Cunha fiscal, informalidade e crescimento: algumas questões e propostas de políticas. IPEA Texto para Discussão, n. 1068, 2005. 
ULYSSEA, G. Informalidade no mercado de trabalho brasileiro: uma resenha da literatura. Revista de Economia Política, v. 26, n. 4, p. 596-618, 2006.

VINHAIS, H. E. F. Estudo sobre o impacto da expansão das universidades federais no Brasil. 2013. Tese (Doutorado) - Faculdade de Economia, Administração e Contabilidade, Universidade de São Paulo, São Paulo, 2013.

\section{Apêndice A}

Quadro 1 - Descrição das variáveis utilizadas

\begin{tabular}{|c|c|}
\hline $\begin{array}{l}\text { Ocupação } 18 \text { ou } \\
\text { mais }\end{array}$ & $\begin{array}{l}\text { Taxa de ocupação municipal (\%) das pessoas maiores de } 18 \text { anos de } \\
\text { idade. }\end{array}$ \\
\hline Ocupação 18 a 29 & $\begin{array}{l}\text { Taxa de ocupação municipal (\%) das pessoas entre } 18 \text { e } 29 \text { anos de } \\
\text { idade. }\end{array}$ \\
\hline $\begin{array}{l}\text { Ocupação } 50 \text { ou } \\
\text { mais }\end{array}$ & $\begin{array}{l}\text { Taxa de ocupação municipal (\%) das pessoas maiores de } 50 \text { anos de } \\
\text { idade. }\end{array}$ \\
\hline Formal 18 ou mais & $\begin{array}{l}\text { Taxa de formalização do mercado de trabalho municipal (\%) das pessoas } \\
\text { maiores de } 18 \text { anos de idade. }\end{array}$ \\
\hline Formal 18 a 29 & $\begin{array}{l}\text { Taxa de formalização do mercado de trabalho municipal (\%) das pessoas } \\
\text { entre } 18 \text { e } 29 \text { anos de idade. }\end{array}$ \\
\hline Formal 50 ou mais & $\begin{array}{l}\text { Taxa de formalização do mercado de trabalho municipal (\%) das pessoas } \\
\text { maiores de } 50 \text { anos. }\end{array}$ \\
\hline $\begin{array}{l}\text { C_Própria } 18 \text { ou } \\
\text { mais }\end{array}$ & $\begin{array}{l}\text { Taxa municipal das pessoas que trabalham por conta própria (\%) } \\
\text { maiores de } 18 \text { anos de idade. }\end{array}$ \\
\hline C_Própria 18 a 29 & $\begin{array}{l}\text { Taxa municipal das pessoas que trabalham por conta própria (\%) entre } \\
18 \text { e } 29 \text { anos de idade. }\end{array}$ \\
\hline $\begin{array}{l}\text { C_Própria } 50 \text { ou } \\
\text { mais }\end{array}$ & $\begin{array}{l}\text { Taxa municipal das pessoas que trabalham por conta própria (\%) } \\
\text { maiores de } 50 \text { anos de idade. }\end{array}$ \\
\hline $\begin{array}{l}\text { Empregador } 18 \text { ou } \\
\text { mais }\end{array}$ & Taxa municipal dos empregadores (\%) maiores de 18 anos de idade. \\
\hline $\begin{array}{l}\text { Empregador } 18 \\
\text { a } 29\end{array}$ & Taxa municipal dos empregadores (\%) entre 18 e 29 anos de idade. \\
\hline $\begin{array}{l}\text { Empregador } 50 \text { ou } \\
\text { mais }\end{array}$ & Taxa municipal dos empregadores (\%) maiores de 50 anos de idade. \\
\hline $\begin{array}{l}\text { Tx de Ativ. } 18 \text { ou } \\
\text { mais }\end{array}$ & $\begin{array}{l}\text { Taxa municipal de atividade (população economicamente ativa/ } \\
\text { população em idade ativa) (\%) maiores de } 18 \text { anos de idade. }\end{array}$ \\
\hline Tx de Ativ 18 a 29 & $\begin{array}{l}\text { Taxa municipal de atividade (população economicamente ativa/ } \\
\text { população aem idade Ativa) (\%) entre } 18 \text { e } 29 \text { anos de idade. }\end{array}$ \\
\hline $\begin{array}{l}\text { Tx de Ativ } 50 \text { ou } \\
\text { mais }\end{array}$ & $\begin{array}{l}\text { Taxa municipal de atividade (população economicamente ativa/ } \\
\text { população em idade ativa) (\%) maiores de } 50 \text { anos de idade. }\end{array}$ \\
\hline Expansão_IF’s & $\begin{array}{l}\text { Variável binária dos municípios que receberam campi de IFs entre } 2000 \\
\text { e 2010, sendo um para os municípios que receberam campi e zero, caso } \\
\text { contrário. }\end{array}$ \\
\hline
\end{tabular}

continua... 
conclusão.

\begin{tabular}{|l|l|}
\hline Expansão_Univ. & $\begin{array}{l}\text { Variável binária dos municípios que receberam campi de UFs entre 2000 } \\
\text { e 2010, sendo um para os municípios que receberam campi e zero, caso } \\
\text { contrário. }\end{array}$ \\
\hline Interação & Interação entre as variáveis binárias Expansão_IF's e Expansão_Univ. \\
\hline Urbano & $\begin{array}{l}\text { Percentual de pessoas residentes em domicílios localizados na zona } \\
\text { urbana. }\end{array}$ \\
\hline Homem & Percentual de homens do município. \\
\hline Branco & Percentual de pessoas brancas do município. \\
\hline idade0a14anos & Percentual de pessoas de 0 a 14 anos de idade. \\
\hline idade15a24anos & Percentual de pessoas de 15 a 24 anos de idade. \\
\hline idade25a59anos & Percentual de pessoas de 25 a 59 anos de idade. \\
\hline idade60anos & Percentual de pessoas de 60 ou mais anos de idade. \\
\hline Taxa_Alfabetização & Percentual de pessoas alfabetizadas do município. \\
\hline
\end{tabular}

Fonte: Elaboração própria.

Nota: (*) Foram considerados trabalhadores formais aqueles com carteira de trabalho assinada, ou funcionários públicos ou empregadores. 


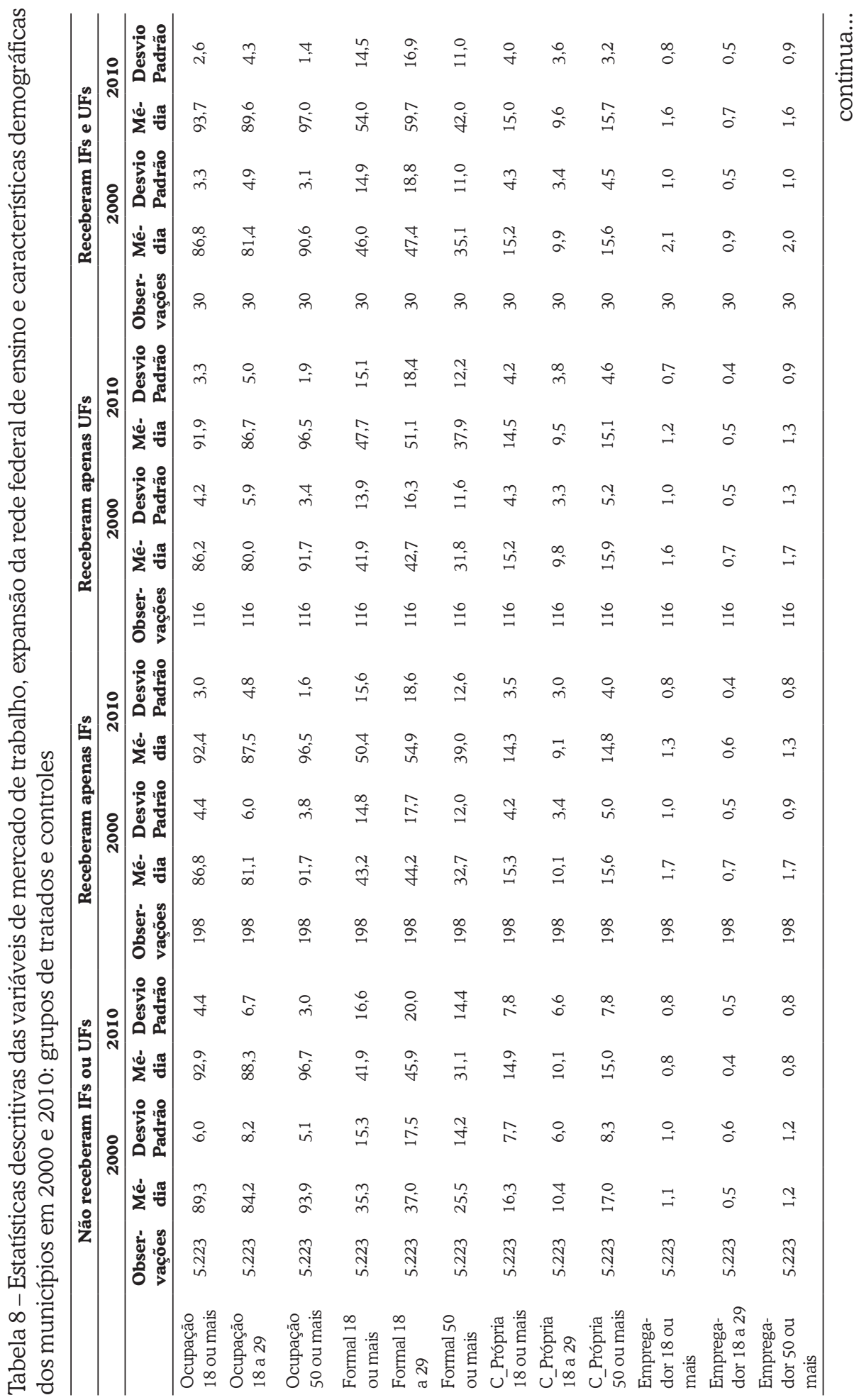

294 Análise Econômica, Porto Alegre, v. 38, n. 77, p. 259-296, set. 2020. 


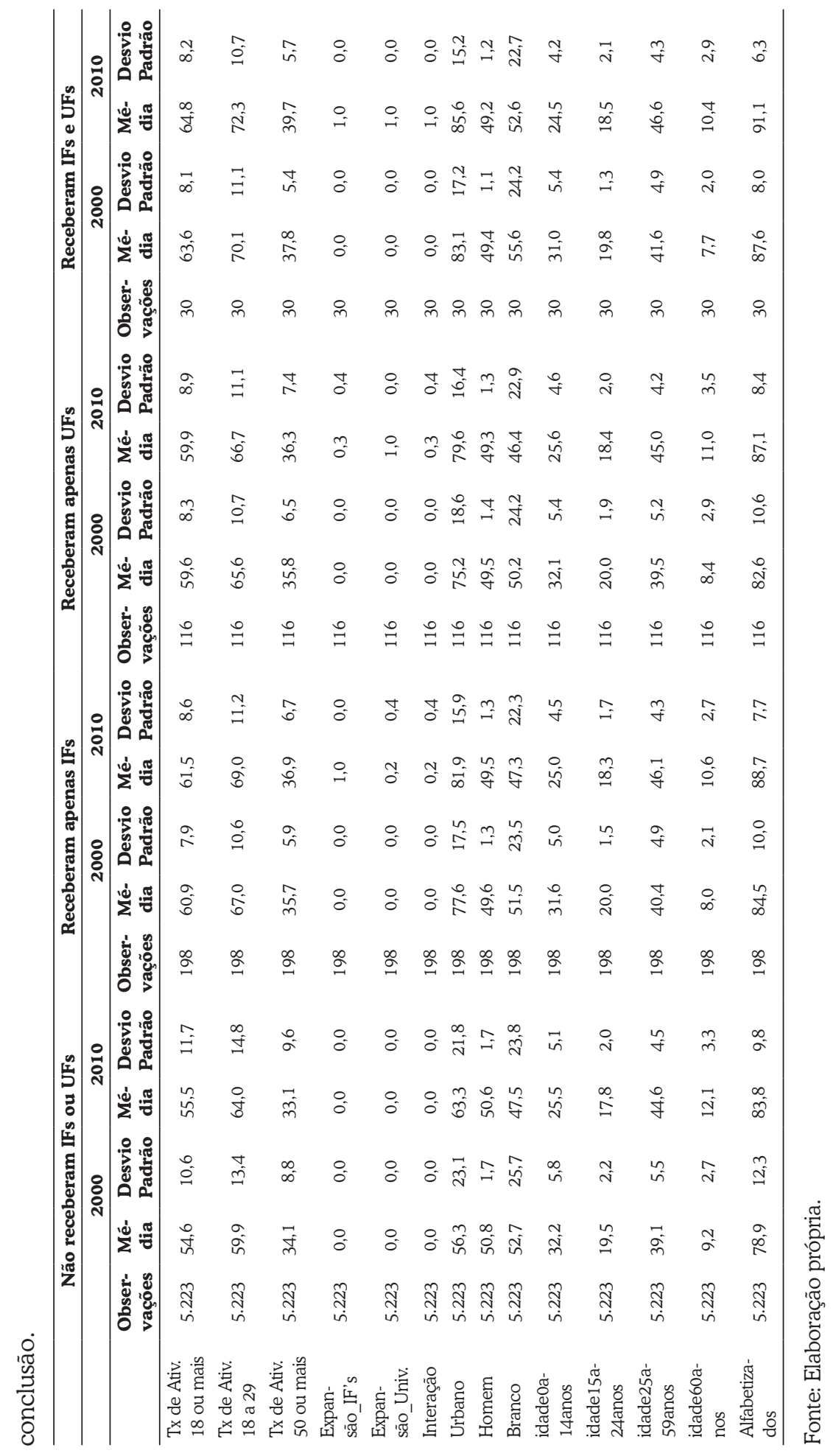

Análise Econômica, Porto Alegre, v. 38, n. 77, p. 259-296, set. 2020. 
Autor correspondente:

Recebido em: 13/11/2017.

Felipe Garcia Ribeiro

Aceito em: 27/12/2017.

E-mail: felipe.garcia.rs@gmail.com

\section{(cc) BY}

